\title{
Identification of key genes involved in the phenotypic alterations of res (restored cell structure by salinity) tomato mutant and its recovery induced by salt stress through transcriptomic analysis
}

\author{
Irene Albaladejo ${ }^{1 \dagger}$, Isabel Egea ${ }^{1 * \dagger}$ (D), Belen Morales ${ }^{1}$, Francisco B. Flores ${ }^{1}$, Carmen Capel $^{2}$, Rafael Lozano ${ }^{2}$
} and Maria C. Bolarin

\begin{abstract}
Background: The res (restored cell structure by salinity) mutant, recently identified as the first tomato mutant accumulating jasmonate in roots under non-stressful conditions, exhibits a remarkable growth inhibition and morphological alterations in roots and leaves, which are suppressed when the mutant plants are exposed to salinity. In order to understand the molecular basis of the phenotype recovery induced by salt stress in the res mutant, we carried out a comparative transcriptomic analysis in roots and leaves of wild-type and res plants in absence of stress (control) and when the phenotypic recovery of res mutant began to be observed upon salt stress (5 days of $200 \mathrm{mM} \mathrm{NaCl}$ ).
\end{abstract}

Results: The number of differentially expressed genes was three times greater in roots than in leaves of res vs WT plants grown in control, and included the down-regulation of growth-promoting genes and the up-regulation of genes involved in $\mathrm{Ca}^{2+}$ signalling, transcription factors and others related to stress responses. However, these expression differences were attenuated under salt stress, coinciding with the phenotypic normalisation of the mutant. Contrarily to the attenuated response observed in roots, an enhanced response was found in leaves under salt stress. This included drastic expression changes in several circadian clock genes, such as GIGANTEA1, which was down-regulated in res vs WT plants. Moreover, the higher photosynthetic efficiency of res leaves under salt stress was accompanied by specific salt-upregulation of the genes RUBISCO ACTIVASE1 and ALTERNATIVE OXIDASE1A. Very few genes were found to be differentially expressed in both tissues (root and leaf) and conditions (control and salt), but this group included SIWRKY39 and SIMYB14 transcription factors, as well as genes related to protein homeostasis, especially protease inhibitors such as METALLOCARBOXYPEPTIDASE INHIBITOR, which also seem to play a role in the phenotype recovery and salt tolerance of res mutant.

Conclusions: In summary, in this study we have identified genes which seem to have a prominent role in salt tolerance. Moreover, we think this work could contribute to future breeding of tomato crops with increased stress tolerance.

Keywords: Solanum lycopersicum, res mutant, Microarrays, Growth-defence tradeoff, Salt stress

\footnotetext{
* Correspondence: iegea@cebas.csic.es

${ }^{+}$Irene Albaladejo and Isabel Egea contributed equally to this work.

'Departamento de Biología del Estrés y Patología Vegetal, Centro de

Edafología y Biología Aplicada del Segura, CSIC, Campus Universitario

Espinardo, 30100 Murcia, Spain

Full list of author information is available at the end of the article
}

(c) The Author(s). 2018 Open Access This article is distributed under the terms of the Creative Commons Attribution 4.0 International License (http://creativecommons.org/licenses/by/4.0/), which permits unrestricted use, distribution, and

reproduction in any medium, provided you give appropriate credit to the original author(s) and the source, provide a link to the Creative Commons license, and indicate if changes were made. The Creative Commons Public Domain Dedication waiver (http://creativecommons.org/publicdomain/zero/1.0/) applies to the data made available in this article, unless otherwise stated. 


\section{Background}

Agriculture is probably facing its biggest challenge in human history due to world climate change, as the average global earth surface temperature is significantly rising, drastically affecting global agricultural systems, especially in arid and semi-arid areas, which represent about one-third of the planet surface [1]. In these areas, salinization is another important problem caused by the frequent use of irrigation waters that contain salts as $\mathrm{NaCl}$. To face this situation, it is crucial to unravel the key components of the plant salt-tolerance network [2], as advances in the understanding of stress signalling and responses will increase our ability to improve stress resistance in crops, and thus to achieve agricultural sustainability and food security for a growing world population [3]. A generic signal transduction pathway starts with the perception of outside signals, followed by a series of intracellular reactions, including the generation of second messengers, changes in intracellular $\mathrm{Ca}^{2+}$ levels, the initiation of a protein phosphorylation cascade, and finally, the activation of target proteins directly involved in cellular protection or transcription factors (TFs) controlling specific sets of stress-regulated genes $[2,4,5]$.

Plant hormones are central regulators of complex developmental processes and stress-adaptative signalling cascades [6], and it has been suggested that the balance between different hormones determines the appropriate response to an experienced stress [7]. Among them, jasmonate (JA) is considered a key regulator of stress responses in virtually all plant species [8,9]. There is increasing evidence that JA mediates multiple stress responses, from biotic stresses and mechanical wounding to different abiotic stresses, including salinity $[10,11]$, although the activation of JA signalling severely restricts plant growth [12]. Recently, we identified the res tomato mutant, which in absence of stress presented remarkable morphological alterations, growth inhibition and cellular disorganization in roots and leaves, including alterations in chloroplast structure [13]. Moreover, this mutant contains high JA level and increased expression of genes involved in JA biosynthesis and signalling pathways in roots, plant organ where investigations are scarce, as most of studies on tolerance induced by JA to abiotic and biotic stresses are referred to its biosynthesis in leaves $[8,14]$. Surprisingly, under salt stress the res mutant was able to restore a normal phenotype and cell structure, which in turn resulted in increased growth of res plants [13]. Moreover, res plants were also able to recover a normal phenotype when exposed to high temperatures and low relative humidity in the natural summer conditions of the Mediterranean area [15]. In sum, res mutant seems to be prepared to confront abiotic stresses and growth inhibition may represent the cost for that benefit. In this sense, the tolerance of halophytic species is generally accompanied by slow plant development, which has been attributed to the energetic cost that implies high basal levels of genes in absence of stress $[16,17]$.

In tomato (Solanum lycopersicum), considered one of the most economically important horticultural crops grown worldwide [18], and a highly important crop in agriculture of arid and semi-arid zones, studies of mutants with constitutive stress responses are very scarce, despite the analysis of these kind of mutants may be very helpful to identify key genes involved in plant adaptation and survival upon salt stress [19]. The comparative transcriptomic analysis between the tomato res mutant and its background genotype (cv Moneymaker) revealed a constitutive alteration of an important number of genes involved in different pathways in res mutant, and identified genes specifically overexpressed under salt stress and responsible of both maintaining plant growth and promoting stress tolerance in res mutant.

\section{Results}

The res mutant is chlorotic from the cotyledon stage (Fig. 1a), and maintains leaf chlorosis throughout the plant development (Additional file 1: Figure S1), but is able to restore a normal phenotype under salt stress [13]. In order to elucidate the molecular basis involved in the phenotype recovery induced by salinity in res, we previously selected a time of salt exposure corresponding to the middle of the phenotype recovery. The period of salt stress applied ( 5 days of $200 \mathrm{mM} \mathrm{NaCl}$ ) was selected because the phenotypic normalisation of res mutant began to be observed in leaves and roots (Fig. 1b, Additional file 1: Figure S1). Moreover, at this time the chlorophyll and photosynthetic efficiency values in leaves of salt-treated res plants were at least twice greater than those of the res control leaves and around 50\% compared to leaves of WT (Fig. 1c). We also observed that MDA content, which allows the estimation of oxidative damage on plants, was lower in the leaves of the mutant compared to those of WT, both in control and salt stress (Fig. 1c). On the other hand, WT plants did not show significant physiological changes after this period of salt treatment compared to non-stressful conditions, which agrees with our previous research with WT plants under these conditions [13].

\section{Comparative transcriptome analysis between res mutant and WT plants in absence of stress and after salt treatment}

Regarding the transcriptomic analysis, the comparison of res vs WT grown in control allowed to identify constitutive gene expression differences between genotypes, whereas res vs WT in salt stress identified DEGs in salinity, which may be constitutive or not; in addition, each genotype was compared in salt stress vs control, in order to detect transcripts specifically altered by salinity in WT and mutant plants. A summary of the differences 

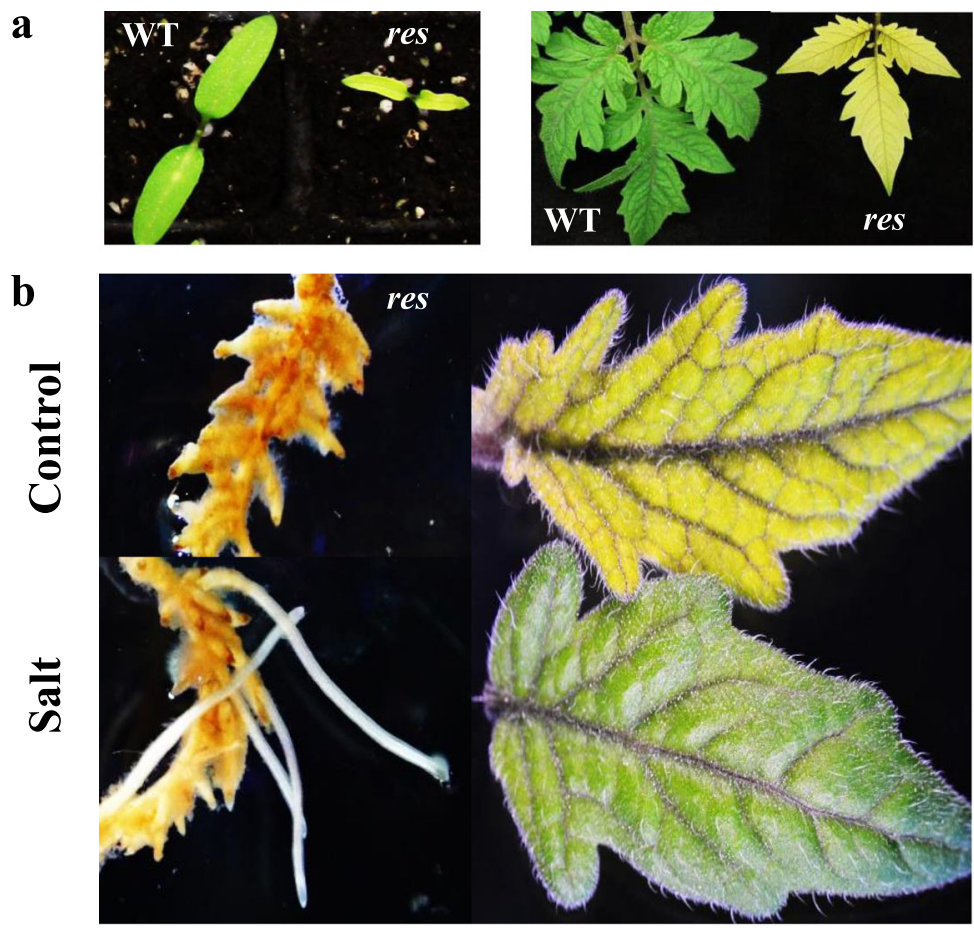

c

$\square \mathrm{WT}$-Control $\mathbf{\nabla} \mathrm{WT}-$ Salt $\square$ res-Control $\mathbf{\Delta}$ res-Salt
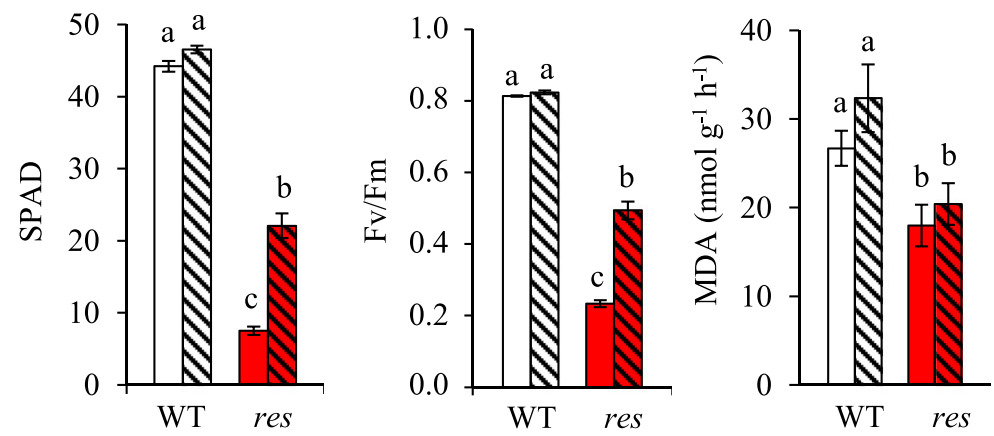

Fig. 1 Normalisation of the res tomato mutant phenotype. (a) Comparison of WT and res seedlings (left) and leaves of adult plants (right) in absence of salt stress. (b) Phenotypic changes provoked by salt treatment ( 5 days at $200 \mathrm{mM} \mathrm{NaCl}$ ) in roots and leaves of res. (c) Chlorophyll content (SPAD), photosynthetic efficiency (Fv/Fm) and MDA content measured in WT (white bars) and res (red bars) leaves under control conditions (plain coloured bars) and after 5 days of salt stress (dashed coloured bars). Values are means \pm SE of three biological replicates. Different letters indicate significant differences between means by LSD test $(P<0.05)$

observed when comparing the transcriptome of WT and res plants in each treatment is presented in Fig. 2. DEGs between WT and res mutant were very high (3046 DEGs) in roots under control conditions, whereas only 295 DEGs (approximately a 10\%) were detected in salt-stressed roots (Fig. 2a). However, the DEG number in leaves was slightly lower in control than in salt (1019 and 1366 DEGs, respectively), of which only 241 (a 20\% approximately) were common to both conditions. These results indicate that salt stress greatly reduced the number of DEGs between WT and res roots, whereas in leaves each condition stimulated specific subsets of genes, being slightly higher the number of DEGs in salt-stressed leaves. Moreover, we found that the majority of DEGs were tissue-specific (Fig. 2b). The reduction of DEGs in res vs WT roots under salt stress coincided with a significant difference in the magnitude of the transcriptomic response of each genotype in salt vs control (Additional file 2: Figure S2a). Thus, 1726 DEGs were found in salt-stressed res roots compared to non-stressed ones, and only 428 DEGs in WT. However, a high number of DEGs were detected in salt-treated vs 

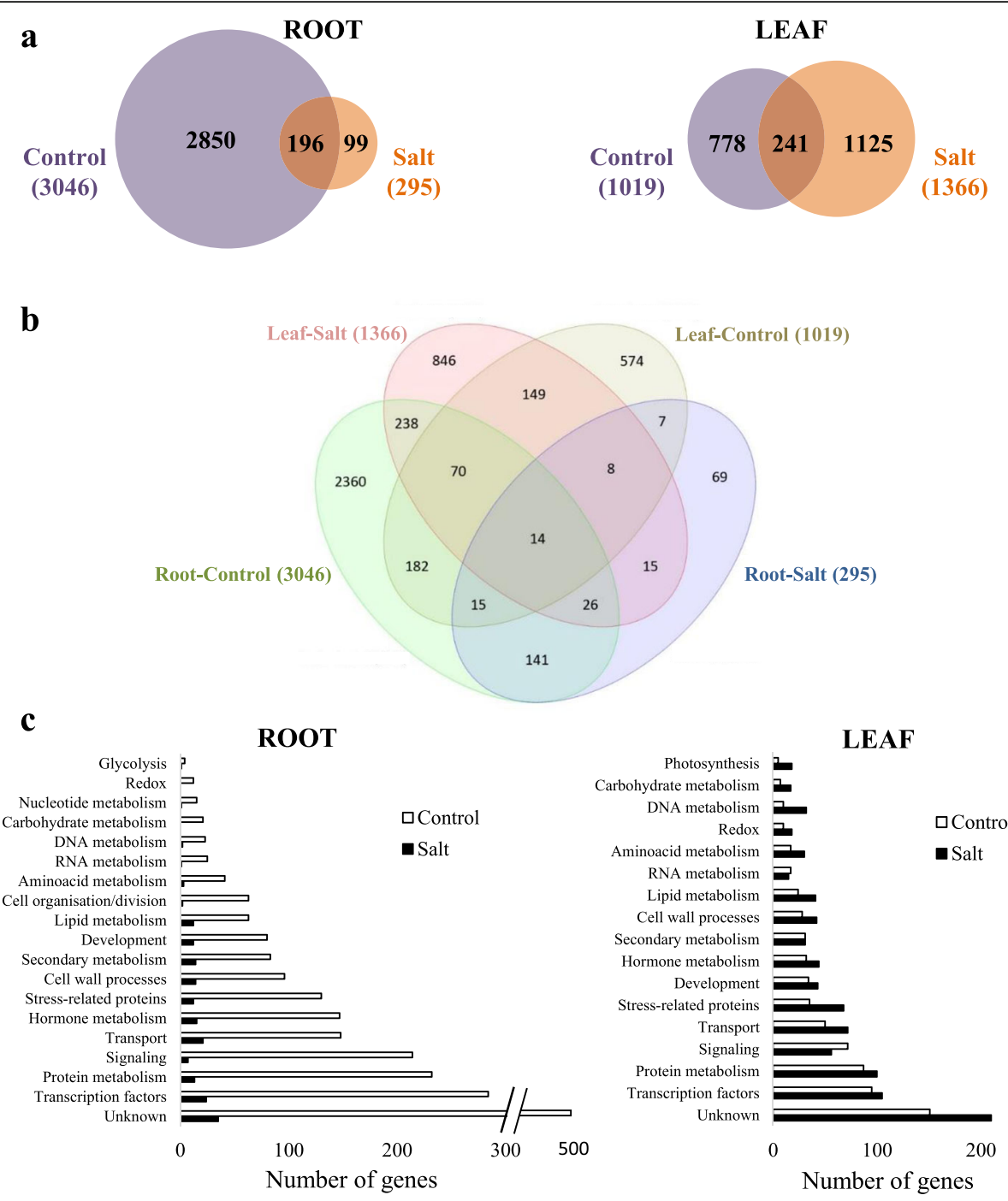

Fig. 2 Gene expression differences between WT and res plants in roots and leaves. (a) Venn diagrams showing the number of differentially expressed genes (DEGs) comparing WT and res in absence of salt stress (control) and exposed to $200 \mathrm{mM} \mathrm{NaCl}$ for 5 days (Salt), as well as the overlap of genes commonly expressed in both conditions. Numbers in parentheses are the total number of DEGs in control and salt stress in both tissues. DEGs are those showing a FDR $<0.05$ and a minimum fold-change value of 2.0. (b) Four-way Venn diagram showing the relationship between DEGs identified in each tissue and treatment. Leaf-Control and Root-Control represent DEGs in res vs WT in each tissue in absence of salt stress, whereas Leaf-Salt and Root-Salt include DEGs in res vs WT in each tissue during salt stress. (c) Number of DEGs classified in functional categories for each tissue using Mapman, both in control and salt stress

control leaves of both genotypes (2793 in WT and 2169 in res), of which more than $50 \%$ were specifically altered in each genotype (Additional file 2: Figure S2a).

Functional classification of DEGs was carried out using the Mapman bin system [20]. The functional categories showing the highest number of DEGs between res and WT included genes with unknown function (around 15\% of DEGs in each tissue and condition), followed by TFs, protein metabolism and signalling in both roots and leaves (Fig. 2c). Moreover, most of these functional categories coincided when considering DEGs in salt stress vs control for each genotype (Additional file 2: Figure S2b). The complete Mapman gene lists of relevant functional categories for each comparison (res vs WT in control and salt, as well as salt vs control for each genotype), are included in Additional files 3, 4, 5, 6, 7, 8 and 9: Tables S2-S8. Mapman diagrams showing that highly-altered functional groups were integrated within stress responses is presented in Additional file 10: Figure S3. In addition, selected DEGs with high up- and down-regulation are presented for each functional category and described in the following sections (Tables 1, 2, 3, 4, 5, 6, 7).

\section{Genes related to hormone metabolism and signalling pathways}

One of the main differences in gene expression between res and WT was related to hormone metabolism 
Table 1 Genes involved in hormone metabolism showing high expression differences in roots and leaves of res and WT plants in absence of salt stress (Control) and after 5 days of $200 \mathrm{mM} \mathrm{NaCl}$ (Salt). Fold-change values are shown, comparing res vs WT in each condition (left columns) or salt stress vs control for each genotype (right columns). Fold-change values are also displayed by a colour scale, where blue represents down-regulation and red up-regulation in each given comparison

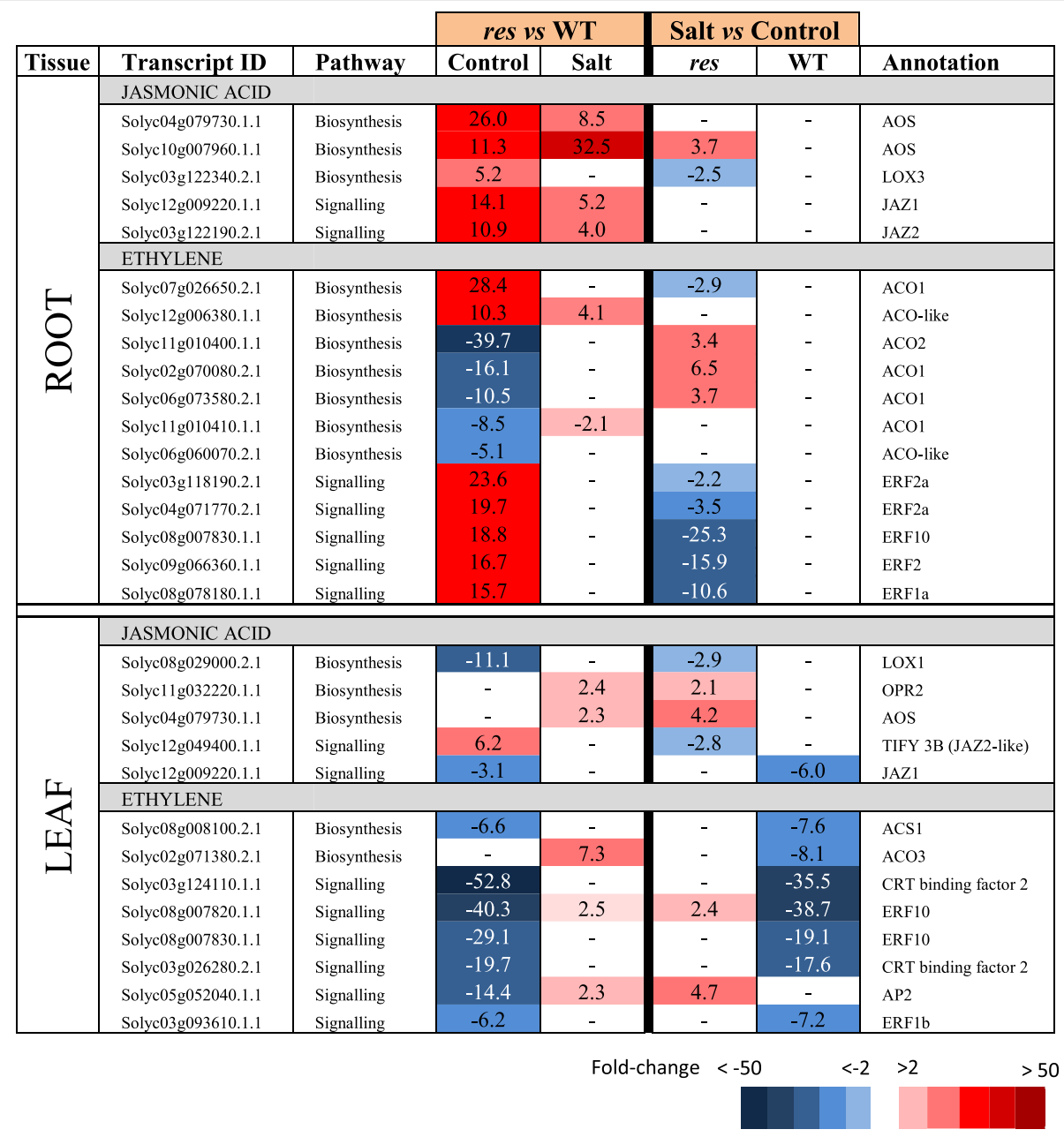

(Additional file 3: Table S2), and concretely JA and ethylene (ET) metabolism genes showed the highest transcript differences between WT and res (Table 1). In roots, transcripts of genes related to JA biosynthesis $(A O S, L O X)$ and signalling $(J A Z)$ were significantly up-regulated in res vs WT, and expression differences were generally reduced in salt. Regarding ET, in roots no clear trend was observed for biosynthesis genes, whereas several ETHYLENE RESPONSE FACTORS (ERFS) genes were constitutively overexpressed. In leaf, however, most genes related to ET metabolism were down-regulated in control. Finally, in both tissues, most expression differences were reduced or disappeared in salt stress (Table 1).

The transcriptomic profiles of genes involved in signalling pathways differed significantly between roots and leaves in control plants (Additional file 4: Table S3), as most genes showing high expression differences were up-regulated in res roots and down-regulated in res leaves compared to WT (Table 2). Among the genes induced in non-stressed res roots we found a group of $\mathrm{Ca}^{2}$ ${ }^{+}$-binding proteins such as calmodulins, a calreticulin, two $\mathrm{Ca}^{2+}$-transporting ATPases and a high number of receptor-like kinases. Contrarily, in leaves most of these genes were down-regulated in res compared to WT plants, with some exceptions like the gene encoding GUANYLATE-BINDING PROTEIN 1, classified by Mapman as putatively involved in G-protein signalling, which was highly up-regulated in res compared to WT leaves both in control and salt stress. The opposite response in roots and leaves was clearly shown by some transcripts found in both tissues. For example, Solyc03g118810.1.1 and Solyc11g071740.1.1, encoding a calmodulin and a calmodulin-like protein, respectively, and two LRR receptor-like serine/threonine protein 
Table 2 Selected genes involved in signalling pathways with high expression differences in roots and leaves of res and WT plants in absence of salt stress (Control) and after 5 days of $200 \mathrm{mM} \mathrm{NaCl}$ (Salt). Fold-change values are shown, comparing res vs WT in each condition (left columns) or salt stress vs control for each genotype (right columns). Fold-change values are also displayed by a colour scale, where blue represents down-regulation and red up-regulation in each given comparison

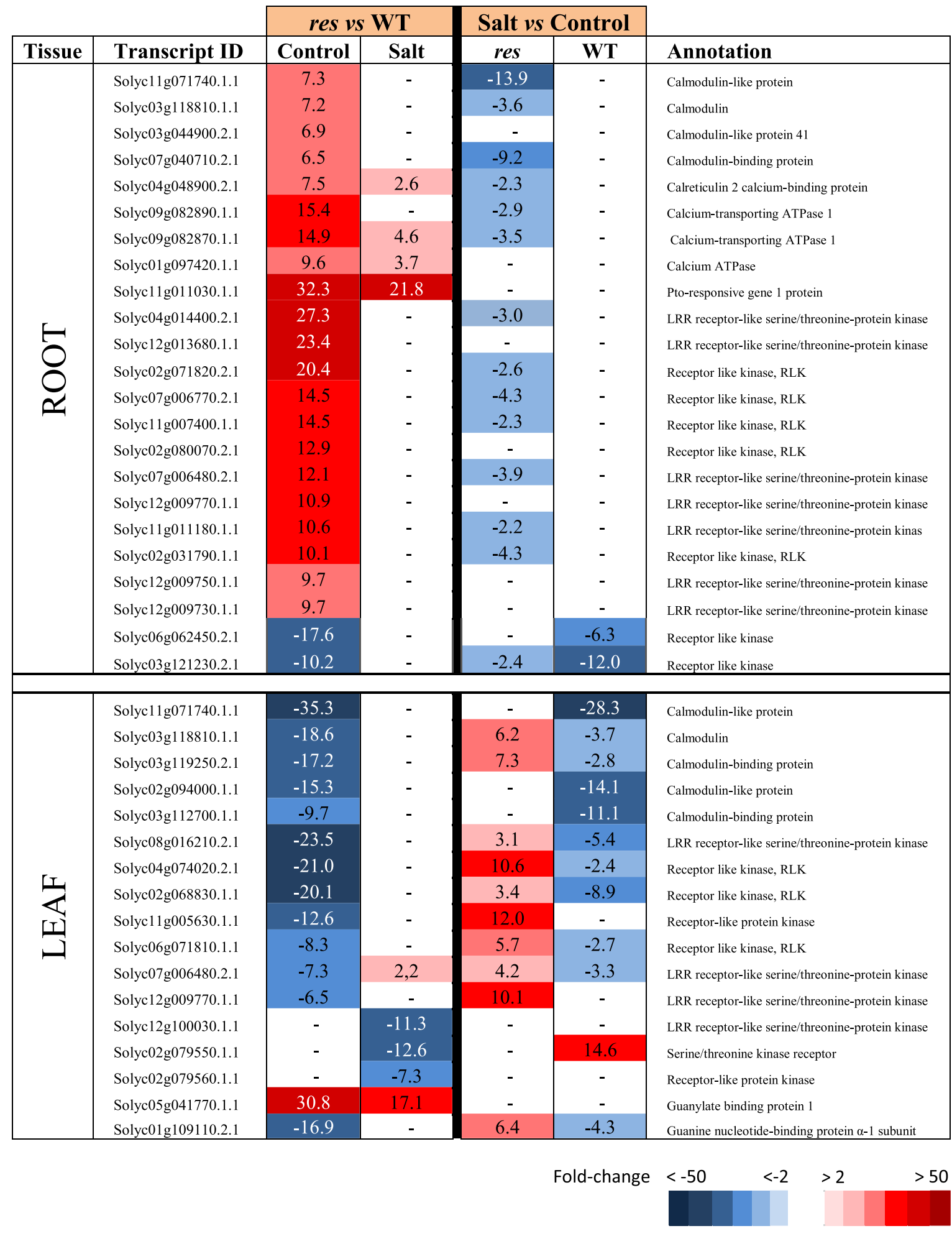


Table 3 Selected DEGs encoding transcription factors showing high expression differences in roots and leaves of res and WT plants in absence of salt stress (Control) and after 5 days of $200 \mathrm{mM} \mathrm{NaCl}$ (Salt), considering the comparison between genotypes (res vs WT) for each treatment (left columns), and treatments (salt vs control) for each genotype (right columns). Colour panels and values display fold change values, where blue colour and negative data represent down-regulation, whereas red colour and positive data mean up-regulation

\begin{tabular}{|c|c|c|c|c|c|c|}
\hline \multirow[b]{2}{*}{ Tissue } & \multirow[b]{2}{*}{ Gen ID } & \multicolumn{2}{|c|}{ res vs WT } & \multicolumn{2}{|c|}{ Salt vs Control } & \multirow[b]{2}{*}{ Annotation } \\
\hline & & Control & Salt & res & WT & \\
\hline \multirow{16}{*}{$\underset{\gamma}{0}$} & Solyc07g056280.2.1 & 28.4 & 9.0 & -2.4 & - & SIWRKY-30 \\
\hline & Solyc $05 \mathrm{~g} 015850.2 .1$ & 22.5 & - & -3.9 & - & \\
\hline & Solyc03g116890.2.1 & 13.3 & 2.3 & -4.4 & - & SIWRKY-39 \\
\hline & Solyc03g007380.1.1 & 10.7 & - & -3.6 & - & SIWRKY-52 \\
\hline & Solyc01g079260.2.1 & 7.9 & - & - & - & SIWRKY-23 \\
\hline & Solyc $04 \mathrm{~g} 051690.2 .1$ & 7.0 & - & - & - & SlWRKY-51 \\
\hline & Solyc02g071130.2.1 & 5.1 & - & - & - & \\
\hline & Solyc12g099140.1.1 & 20.9 & - & -5.7 & - & SIMYB-108 \\
\hline & Solyc03g119370.1.1 & 14.2 & - & -3.3 & - & SIMYB-116 \\
\hline & Solyc $06 \mathrm{~g} 083900.2 .1$ & 9.6 & 12.5 & - & - & SIMYB-14 \\
\hline & Solyc03g093930.2.1 & 8.6 & - & -3.0 & - & SIMYB-63 \\
\hline & Solyc12g008670.1.1 & 7.4 & - & -5.6 & - & SIMYB-38 \\
\hline & Solyc09g090130.2.1 & 6.2 & 2.8 & -3.4 & - & SIMYB-13 \\
\hline & Solyc03g093940.1.1 & 5.8 & - & -3.9 & - & SIMYB-81 \\
\hline & Solyc05g053330.2.1 & 5.8 & - & -2.9 & - & SIMYB-2 \\
\hline & Solyc03g093890.2.1 & 5.2 & - & -3.9 & - & SIMYB-58 \\
\hline & Solyc $08 \mathrm{~g} 082110.2 .1$ & -63.6 & - & 6.0 & -14.2 & SIWRKY-54 \\
\hline & Solyc09g014990.2.1 & -49.7 & 2.1 & 6.9 & -11.3 & SIWRKY-33 \\
\hline & Solyc $08 \mathrm{~g} 008280.2 .1$ & -48.8 & - & 9.8 & -12.4 & SIWRKY-53 \\
\hline & Solyc04g051690.2.1 & -8.3 & - & - & -5.7 & SIWRKY-51 \\
\hline & Solyc06g066370.2.1 & -7.8 & - & 3.8 & -2.5 & SIWRKY-31 \\
\hline & Solyc06g068460.2.1 & -6.1 & - & 2.5 & -3.5 & SIWRKY-40 \\
\hline & Solyc08g067340.2.1 & -5.9 & - & 14.1 & 4.1 & SIWRKY-46 \\
\hline & Solyc03g116890.2.1 & -5.1 & 6.8 & 2.3 & -14.4 & SIWRKY-39 \\
\hline & Solyc01g079260.2.1 & - & 3.8 & - & -4.9 & SIWRKY-23 \\
\hline & Solyc $06 \mathrm{~g} 083900.2 .1$ & 30.3 & 7.6 & -5.0 & - & SIMYB-14 \\
\hline 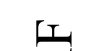 & Solyc12g008800.1.1 & 10.0 & - & -2.3 & 2.5 & MYB transcription factor \\
\hline & Solyc04g005600.1.1 & 6.4 & - & -6.5 & - & SIMYB-51 \\
\hline & Solyc06g065100.2.1 & 5.6 & - & - & 4.7 & SIMYB-3 \\
\hline & Solyc03g098320.2.1 & - & 17.8 & - & -45.7 & MYB transcription factor \\
\hline & Solyc11g073120.1.1 & - & 7.5 & - & -8.3 & SIMYB-48 \\
\hline & Solyc01g095030.2.1 & - & 5.0 & - & -7.0 & MYB transcription factor ARS1 \\
\hline & Solyc $\log 005080.2 .1$ & - & 36.2 & -2.4 & -131.9 & Circadian clock associated-1, CCA1 \\
\hline & Solyc06g051680.1.1 & - & -133.9 & - & - & ELF4-like protein \\
\hline & Solyc03g081240.2.1 & - & -66.6 & - & 74.6 & Pseudo response regulator \\
\hline & Solyc01g006680.2.1 & - & -56.9 & - & 54.4 & jumonji jmjC domain protein \\
\hline & Solyc $01 \mathrm{~g} 005300.2 .1$ & - & -44.0 & - & 36.0 & FKF-1 - Flavin-binding kelch domain $\mathrm{F}$ box \\
\hline & Solyc03g115770.2.1 & - & -21.1 & - & 5.0 & Timing of $\mathrm{CAB}$ expression-like, TOC1-like \\
\hline & Solyc05g024010.2.1 & - & -17.9 & - & 46.3 & CONSTANS-like zinc finger protein \\
\hline & Solyc04g071990.2.1 & - & -15.2 & - & 44.9 & Tomato GIGANTEA 1 \\
\hline
\end{tabular}


Table 4 Selected DEGs encoding stress-related proteins showing high expression differences in roots and leaves of res and WT plants in absence of salt stress (Control) and after 5 days of $200 \mathrm{mM} \mathrm{NaCl}$ (Salt), considering the comparison between genotypes (res vs WT) for each treatment (left columns), and treatments (salt vs control) for each genotype (right columns). Colour panels and values display fold change values, where blue colour and negative data represent down-regulation, whereas red colour and positive data mean up-regulation

\begin{tabular}{|c|c|c|c|c|c|c|}
\hline \multirow[b]{2}{*}{ Tissue } & \multirow[b]{2}{*}{ Transcript ID } & \multicolumn{2}{|c|}{ res vs WT } & \multicolumn{2}{|c|}{ Salt vs Control } & \multirow[b]{2}{*}{ Annotation } \\
\hline & & Control & Salt & res & WT & \\
\hline \multirow{29}{*}{$\stackrel{+}{0}$} & Solyc09g082280.2.1 & 32.3 & -11.6 & - & 517.1 & Non-specific lipid-transfer protein \\
\hline & Solyc03g083990.1.1 & 23.9 & - & -20.0 & - & Plant lipid transfer protein \\
\hline & Solyc12g014630.1.1 & 17.1 & 9.6 & - & - & Plant lipid transfer protein \\
\hline & Solyc12g014620.1.1 & 10.3 & - & - & - & Plant lipid transfer protein \\
\hline & Solyc03g005200.2.1 & -8.1 & - & - & - & Plant lipid transfer protein \\
\hline & Solyc06g054060.1.1 & - & -10.6 & - & - & Non-specific lipid-transfer protein \\
\hline & Solyc09g065430.2.1 & - & -6.2 & - & 7.2 & Non-specific lipid-transfer protein \\
\hline & Solyc03g005210.2.1 & - & -6.1 & - & - & Non-specific lipid-transfer protein \\
\hline & Solyc07g009510.1.1 & 72.5 & - & -2.2 & 61.8 & Chitinase \\
\hline & Solyc07g009500.1.1 & 70.0 & - & - & 99.7 & Chitinase \\
\hline & Solyc09g007010.1.1 & 20.5 & - & -6.9 & - & Pathogenesis related protein PR-1 \\
\hline & Solyc02g082920.2.1 & 15.5 & - & - & 18.3 & Endochitinase \\
\hline & Solyc01g106600.2.1 & 10.0 & - & -3.5 & - & Pathogenesis-related protein 1 \\
\hline & Solyc05g050130.2.1 & 8.1 & - & - & - & Chitinase \\
\hline & Solyc07g006710.1.1 & -7.7 & - & 7.1 & - & Pathogenesis-related protein PR-1 \\
\hline & Solyc07g054780.1.1 & 32.2 & - & - & - & Wound induced protein \\
\hline & Solyc07g052780.2.1 & 21.1 & - & -4.7 & - & Tir, resistance protein \\
\hline & Solyc02g082740.1.1 & 13.5 & - & - & - & Plant disease resistance response protein \\
\hline & Solyc12g097000.1.1 & 9.9 & - & -2.5 & - & Tir, resistance protein \\
\hline & Solyc07g054760.1.1 & 8.6 & - & - & - & Wound induced protein \\
\hline & Solyc12g094660.1.1 & 6.0 & - & -2.0 & - & Cc-nbs-Irr, resistance protein \\
\hline & Solyc02g032030.1.1 & -14.1 & - & - & -3.7 & Plant disease resistance response protein \\
\hline & Solyc12g097090.1.1 & -13.5 & - & 2.8 & - & Plant disease resistance response protein \\
\hline & Solyc08g081780.1.1 & -12.0 & - & 5.9 & - & Plant disease resistance response protein \\
\hline & Solyc10g055190.1.1 & -11.8 & - & - & -3.4 & Plant disease resistance response protein \\
\hline & Solyc01g107540.2.1 & -10.1 & -4.6 & - & -2.5 & PBSP domain-containing protein \\
\hline & Solyc04g010270.1.1 & -7.0 & - & 2.8 & - & Plant disease resistance response protein \\
\hline & Solyc09g091210.2.1 & -6.2 & - & - & - & Plant disease resistance response protein \\
\hline & Solyc $10 \mathrm{~g} 086680.1 .1$ & 6.7 & - & -3.6 & - & Class I heat shock protein \\
\hline \multirow{16}{*}{$\underset{\Xi}{\Perp}$} & Solyc10g075070.1.1 & 10.7 & - & 2.5 & 9.3 & Non-specific lipid-transfer protein \\
\hline & Solyc08g067530.1.1 & 7.7 & - & - & & Non-specific lipid-transfer protein \\
\hline & Solyc10g075090.1.1 & 6.6 & - & 8.7 & 32.4 & Non-specific lipid-transfer protein \\
\hline & Solyc08g005960.1.1 & - & -16.1 & 4.2 & 62.0 & Plant lipid transfer protein \\
\hline & Solyc08g080640.1.1 & -12.0 & -4.7 & - & - & Osmotin-like protein \\
\hline & Solyc08g080650.1.1 & -8.1 & -3.0 & 3.3 & - & Osmotin-like protein \\
\hline & Solyc07g006560.2.1 & 60.3 & - & - & - & Hypersensitive response assisting protein \\
\hline & Solyc01 g095320.2.1 & 7.6 & - & 6.9 & 47.0 & Apoptosis regulator $\mathrm{Bcl}-2$ protein \\
\hline & Solyc01g102840.2.1 & -7.7 & - & 2.0 & -5.8 & Tir-nbs, resistance protein fragment \\
\hline & Solyc04g007320.1.1 & -6.8 & - & 4.1 & -2.9 & Tir-nbs-lrr, resistance protein \\
\hline & Solyc07g054760.1.1 & - & 7.3 & - & - & Wound induced protein \\
\hline & Solyc06g036290.2.1 & - & 12.1 & - & - & Heat shock protein 90 \\
\hline & Solyc11g066100.1.1 & - & 8.5 & - & - & Heat shock protein 70 \\
\hline & Solyc03g123560.2.1 & - & 7.5 & - & -4.5 & Heat shock protein 40 \\
\hline & Solyc06g068500.2.1 & - & -6.8 & - & 6.7 & Heat shock protein DnaJ \\
\hline & Solyc09g092260.2.1 & - & -6.4 & - & 6.3 & Heat shock protein DnaJ \\
\hline
\end{tabular}


Table 5 Selected DEGs involved in protein degradation showing high expression differences in roots and leaves of res and WT plants in absence of salt stress (Control) and after 5 days of $200 \mathrm{mM} \mathrm{NaCl}$ (Salt). Fold-change values are shown, comparing res vs WT in each condition (left columns) or salt stress vs control for each genotype (right columns). Fold-change values are also displayed by a colour scale, where blue represents down-regulation and red up-regulation in each given comparison

\begin{tabular}{|c|c|c|c|c|c|c|}
\hline \multirow{2}{*}{ Tissue } & \multirow[b]{2}{*}{ Transcript ID } & \multicolumn{2}{|c|}{ res vs WT } & \multicolumn{2}{|c|}{ Salt vs Control } & \multirow{2}{*}{ Annotation } \\
\hline & & Control & Salt & res & WT & \\
\hline \multirow{21}{*}{$\stackrel{F}{0}$} & \multicolumn{6}{|c|}{ PROTEASE INHIBITORS } \\
\hline & Solyc00g071180.2.1 & 58.0 & 18.0 & 2.2 & - & \multirow{3}{*}{$\begin{array}{l}\text { Cysteine proteinase inhibitor } \\
\text { Kunitz-type protease inhibitor-like protein } \\
\text { Kunitz trypsin inhibitor }\end{array}$} \\
\hline & Solyc03g098760.1.1 & 20.2 & 89.5 & 4.8 & - & \\
\hline & Solyc03g098740.1.1 & 19.8 & - & -3.2 & 25.4 & \\
\hline & Solyc03g098710.1.1 & 18.6 & 189.5 & 10.1 & - & Kunitz-type proteinase inhibitor A4 \\
\hline & Solyc03g098720.2.1 & 5.3 & 55.2 & 7.9 & - & Kunitz trypsin inhibitor \\
\hline & Solyc09g084460.2.1 & 2.7 & 103.8 & 27.9 & - & Chymotrypsin inhibitor 2 \\
\hline & Solyc07g007250.2.1 & - & 36.4 & 31.3 & - & \multirow{2}{*}{$\begin{array}{l}\text { Metallocarboxypeptidase inhibitor } \\
\text { Proteinase inhibitor I }\end{array}$} \\
\hline & Solyc03g020070.2.1 & - & 23.6 & 18.1 & - & \\
\hline & Solyc09g084490.2.1 & - & 19.8 & 26.2 & - & $\begin{array}{l}\text { Proteinase inhibitor II } \\
\text { Proteinase inhibitor I }\end{array}$ \\
\hline & \multicolumn{6}{|c|}{ PROTEASES / UBIQUITIN-PROTEASOME } \\
\hline & Solyc03g033790.2.1 & 44.1 & - & -2.4 & - & \multirow{10}{*}{$\begin{array}{l}\text { Cell division protease fts homolog } 3 \\
\text { IBR finger domain protein } \\
\text { Prolyl endopeptidase } \\
\text { Zinc finger protein-like protein } \\
\text { RING finger protein } 44 \\
\text { 26S protease regulatory subunit 6B homolog } \\
\text { F-box family protein } \\
\text { U-box domain-containing protein } \\
\text { Cell division protease ftsH homolog } \\
\text { Subtilisin-like protease } \\
\end{array}$} \\
\hline & Solyc03g117860.2.1 & 21.6 & 4.1 & -2.3 & - & \\
\hline & Solyc04g082120.2.1 & 18.9 & - & -2.9 & - & \\
\hline & Solyc03g115920.2.1 & 9.0 & - & - & - & \\
\hline & Solyc03g033330.2.1 & 8.8 & - & - & - & \\
\hline & Solyc03g033840.2.1 & 7.8 & - & - & - & \\
\hline & Solyc03g117270.1.1 & 6.6 & - & - & - & \\
\hline & Solyc11g006030.1.1 & 6.0 & - & -8.0 & - & \\
\hline & Solyc02g062550.2.1 & 5.9 & - & -4.5 & - & \\
\hline & Solyc08g007610.1.1 & - & 5.1 & 2.0 & - & \\
\hline \multirow{17}{*}{$\underset{1}{1}$} & \multicolumn{6}{|c|}{ PROTEASE INHIBITORS } \\
\hline & Solyc07g007250.2.1 & 265.1 & 2.9 & -5.0 & 22.4 & \multirow{11}{*}{$\begin{array}{l}\text { Metallocarboxypeptidase inhibitor } \\
\text { Kunitz-type protease inhibitor } \\
\text { Proteinase inhibitor I } \\
\text { Proteinase inhibitor } \\
\text { Kunitz trypsin inhibitor } 4 \\
\text { Proteinase inhibitor I } \\
\text { Proteinase inhibitor I } \\
\text { Kunitz-type protease inhibitor } \\
\text { Xylanase inhibitor } \\
\text { Kunitz trypsin inhibitor } \\
\text { Proteinase inhibitor I }\end{array}$} \\
\hline & Solyc03g098790.1.1 & 102.8 & 2.8 & -6.4 & 5.0 & \\
\hline & Solyc09g083440.2.1 & 31.5 & - & -2.4 & 32.9 & \\
\hline & Solyc1 1g021060.1.1 & 29.1 & - & -4.5 & 14.5 & \\
\hline & Solyc11g022590.1.1 & 27.4 & 2.1 & -2.6 & 7.8 & \\
\hline & Solyc09g084480.2.1 & 21.7 & - & -8.5 & - & \\
\hline & Solyc09g084490.2.1 & 20.5 & - & -11.7 & - & \\
\hline & Solyc03g098780.1.1 & 14.3 & - & -2.8 & 5.3 & \\
\hline & Solyc01 g080020.2.1 & 3.6 & -5.5 & - & 10.7 & \\
\hline & Solyc03g098730.1.1 & -10.5 & - & 3.3 & -5.8 & \\
\hline & Solyc09g089540.2.1 & - & -5.6 & - & 12.7 & \\
\hline & \multicolumn{6}{|c|}{ PROTEASES / UBIQUITIN-PROTEASOME } \\
\hline & Solyc00g187050.2.1 & 29.1 & - & -4.3 & - & \multirow{4}{*}{$\begin{array}{l}\text { Leucyl aminopeptidase } \\
\text { Predicted: E3 ubiquitin-protein } \\
\text { Leucyl aminopeptidase } \\
\text { Cathepsin B-like cysteine proteinase }\end{array}$} \\
\hline & XM_004248114.1 & 16.5 & - & - & - & \\
\hline & Solyc12g010020.1.1 & 15.9 & - & -5.1 & 3.0 & \\
\hline & Solyc02g076690.2.1 & - & -17.5 & 4.1 & 40.2 & \\
\hline
\end{tabular}

kinases encoded by Solyc07g006480.2.1 and Solyc12g0 09770.1.1, were up-regulated in roots and repressed in leaves of res vs WT plants. Under salt stress, most gene expression differences between res and WT were significantly reduced in roots and leaves. However, whereas in roots this was mainly related to expression changes of res in salt vs control, in leaves it was due to changes induced by salt stress in either res or WT, or in both genotypes.

\section{Genes related to transcription factors and stress-related proteins}

In control roots, the TFs up-regulated in res mutant included a numerous group of WRKYs and MYBs, while in salt stress most expression differences disappeared, in most cases due to their specific down-regulation in res roots under salinity (Additional file 5: Table S4, Table 3). In leaves, MYBs were also up-regulated in res vs WT, and some of them specifically under salt stress, such as SIMYB48 and ARS1. On the other hand, DEGs between res and WT leaves encoding WRKY TFs showed opposite trends under control conditions compared to those observed in roots (for example SlWRKY39). In addition, a group of DEGs involved in circadian rhythm were specifically detected in leaves of res vs WT under salt stress, mainly related to the alteration of these genes in WT leaves upon salinity (Table 3). Interestingly, except the gene encoding MYB-like CIRCADIAN CLOCK ASSOCIATED 1 
Table 6 Selected DEGs involved in developmental processes, cell wall modification and cell cycle and organisation having high expression differences in roots and leaves of res and WT plants in absence of salt stress (Control) and after 5 days of $200 \mathrm{mM} \mathrm{NaCl}$ (Salt), considering the comparison between genotypes (res vs WT) for each treatment (left columns), and treatments (salt vs control) for each genotype (right columns). Colour panels and values display fold change values, where blue colour and negative data represent down-regulation, whereas red colour and positive data mean up-regulation

\begin{tabular}{|c|c|c|c|c|c|c|}
\hline \multirow[b]{2}{*}{ Tissue } & \multirow[b]{2}{*}{ Gen ID } & \multicolumn{2}{|c|}{ res vs WT } & \multicolumn{2}{|c|}{ Salt vs Control } & \multirow[b]{2}{*}{ Annotation } \\
\hline & & Control & Salt & res & WT & \\
\hline \multirow{12}{*}{$\underset{\Omega}{0}$} & Solyc01g097690.2.1 & -214.8 & - & 10.3 & -13.1 & Extensin-like protein Dif54 \\
\hline & Solyc01g097680.2.1 & -50.6 & - & 5.1 & -14.0 & Extensin-like protein Dif10 \\
\hline & Solyc $02 \mathrm{~g} 030220.1 .1$ & -38.0 & - & 11.2 & -26.5 & Extensin-like protein Dif10 \\
\hline & Solyc02g081990.2.1 & -25.8 & -3.0 & 9.1 & - & Pectinesterase \\
\hline & Solyc01g005880.1.1 & -23.6 & - & 8.7 & -18.5 & Extensin-like protein Dif10 \\
\hline & Solyc12g015690.1.1 & -9.1 & - & 4.1 & - & Fasciclin-like arabinogalactan protein 10 \\
\hline & Solyc03g116370.2.1 & -7.4 & - & 2.8 & - & Microtubule plus-end binding protein \\
\hline & Solyc10g047240.1.1 & -7.4 & - & 2.5 & - & Annexin \\
\hline & Solyc12g007260.1.1 & -5.8 & 11,1 & 3.6 & -16.2 & Xyloglucan endotransglucosylase/hydrolase 2 \\
\hline & Solyc01g091530.2.1 & -5.6 & - & 2.2 & - & Fasciclin-like arabinogalactan protein 13 \\
\hline & Solyc05g054480.2.1 & -5.0 & - & 2.3 & - & Actin \\
\hline & Solyc10g086520.1.1 & - & 11,2 & 2.3 & - & Expansin-1 \\
\hline & Solyc07g056000.2.1 & -54.7 & - & - & -26.9 & Xyloglucan endotransglucosylase/hydrolase 7 \\
\hline$I_{1}$ & Solyc03g093110.2.1 & -36.3 & - & - & -34.7 & Xyloglucan endotransglucosylase/hydrolase 9 \\
\hline & Solyc12g017240.1.1 & -29.8 & - & - & -22.3 & Xyloglucan endotransglucosylase/hydrolase 7 \\
\hline & Solyc11g068620.1.1 & -25.4 & 2.1 & - & -10.3 & \multirow{2}{*}{$\begin{array}{l}\text { No apical meristem (NAM) protein } \\
\text { Xyloglucan endotransglucosylase/hydrolase } 9\end{array}$} \\
\hline & Solyc03g093120.2.1 & -18.0 & - & - & -14.1 & \\
\hline & Solyc03g097050.2.1 & -14.3 & - & - & -14.0 & Cellulose synthase-like protein \\
\hline & & & & & d-change & $<-100$ \\
\hline
\end{tabular}

(CCA1), which was up-regulated, the rest were strongly down-regulated in res vs WT, including TIMING OF CAB EXPRESSION1-LIKE (TOC1-LIKE) and GIGANTEA1.

Regarding stress-related DEGs, several lipid transfer proteins (LTPs) were detected in res roots and leaves before any stress was applied, and these genes were generally up-regulated in both plant organs (Additional file 6: Table S5 and Table 4). Moreover, chitinases and pathogenesis-related proteins (PRs) were among the DEGs constitutively overexpressed in control, while other genes associated to biotic stress were down-regulated in res roots. In leaves, there was an increase in the number of DEGs from stress-related proteins in salt compared to control (Fig. 2c), and this included the specific up-regulation of several HEAT SHOCK PROTEIN (HSPS) genes in res compared to WT (Table 4).

\section{Genes involved in protein metabolism}

In absence of stress, a high number of genes involved in protein degradation (proteases) and its regulation (protease inhibitors, PIs), including components of the ubiquitin-proteasome complex, were overexpressed in res roots and leaves compared to WT, with the highest expression differences corresponding to protease inhibitors (Additional file 7: Table S6, Table 5). While DEGs of proteases and ubiquitin-proteasome were mostly reduced in roots upon salt stress, several PIs showed higher overexpression values in salt than in control, especially the KUNITZ-TYPE PROTEINASE INHIBITOR A4. Moreover, other PIs were specifically up-regulated in res roots during salt stress, i.e. the gene METALLOCARBOXYPEPTIDASE INHIBITOR (MPI) (Solyc07g007250.2.1). In fact, this gene showed the highest up-regulation in res 
Table 7 Photosynthesis-related genes with high expression differences in leaves of res and WT plants in absence of salt stress (Control) and after 5 days of $200 \mathrm{mM} \mathrm{NaCl}$ (Salt), considering the comparison between genotypes (res vs WT) for each treatment (left columns), and treatments (salt vs control) for each genotype (right columns). Colour panels and values display fold change values, where blue colour and negative data represent down-regulation, whereas red colour and positive data mean up-regulation

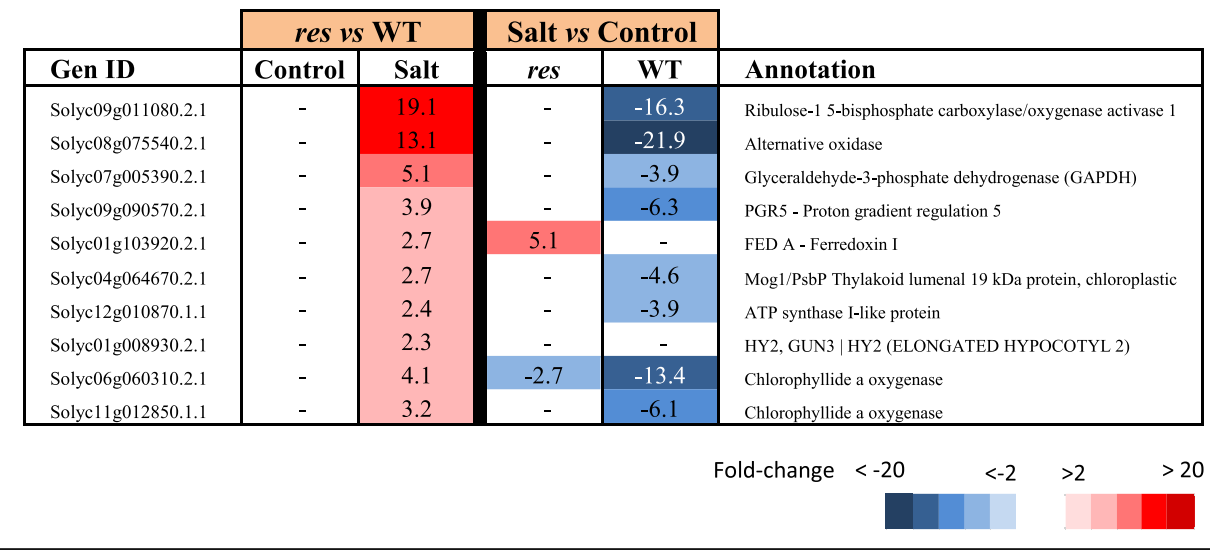

leaves in control conditions. It is also interesting to point out that several protease inhibitors detected are encoded by adjacent loci in the same chromosome (Solyc03g098 710, Solyc03g098720, etc.).

Genes involved in plant development and photosynthesis An important number of genes involved in developmental processes, cell wall modification and cell cycle and organisation were down-regulated in res roots and leaves compared to WT in control conditions (Additional file 8: Table S7, Table 6), which agrees with the important development alterations shown by the res mutant in non-stressful conditions. However, gene expression differences disappeared in salt stress, coinciding with the phenotypic normalisation shown by mutant plants, and this was frequently related to up-regulation of genes previously repressed in res roots, although in some cases it was also due to gene repression induced by salt stress in WT.

In res leaves, significant differences in the expression of genes involved in photosynthesis and other related metabolic processes were found specifically in salt stress (Additional file 9: Table S8, Table 7). Among them, several components of the photosynthetic protein complexes, such as the $P s b P$ subunit of PSII, PGR5, FEDA and ATP SYNTHASE I-LIKE PROTEIN, as well as two genes encoding CHLOROPHYLLIDE A OXYGENASES responsible of chlorophyll b synthesis. Interestingly, two genes that affect photosynthetic efficiency, RUBISCO ACTIVASE 1 (RCA1) (Solyc09g01 1080.2.1) and ALTERNATIVE OXIDASE 1A (AOX1A) (Solyc08g075540.2.1), showed the highest fold-change values in salt-stressed leaves of res compared to WT. In most cases, the differences found between res and
WT were due to the specific down-regulation of these genes in WT leaves under salt stress.

\section{Analysis by RT-qPCR of selected genes (validation of selected DEGs by RT-qPCR)}

Selected genes which seem to have a relevant role in the growth recovery and salt tolerance shown by the res mutant under salt stress were analysed by RT-qPCR. Among important DEGs in root, we tested two genes involved in JA metabolism (AOS and JAZ1) and one of signalling $\left(\mathrm{Ca}^{2+}\right.$-ATPase $)$, and found that salt stress reduced significantly the expression level of these genes in res roots compared to the level obtained in control (Fig. 3), thus corroborating that the constitutive alteration of these genes was attenuated by salt stress. In leaf, the two genes involved in photosynthetic efficiency were analysed, $R C A 1$ and $A O X 1 A$, and the data confirmed the great up-regulation of these genes in res vs WT under salt stress (Fig. 3). Contrarily, the circadian clock component GIGANTEA1 was strongly repressed in res leaves compared to WT under salt stress. There were very few genes with differential expression in both tissues and conditions (14 DEGs), as shown in Fig. 2b, and interestingly two TFs, WRKY39 and MYB14, were included among them. By RT-qPCR analysis (Fig. 3), we observed that WRKY39 showed in root a similar response to that previously observed in JA genes, that is up-regulation in res vs WT in control, but important attenuation in salt stress. However, the expression of MYB14 was not only higher in control but also in salt stress. In leaves, the expression changes of both genes showed opposite tendencies to those observed in roots, as WRKY39 expression increased in res salt vs control, whereas the constitutive high expression of MYB14 found in control leaves of res was strongly reduced by salt stress $(86 \%)$. The other 


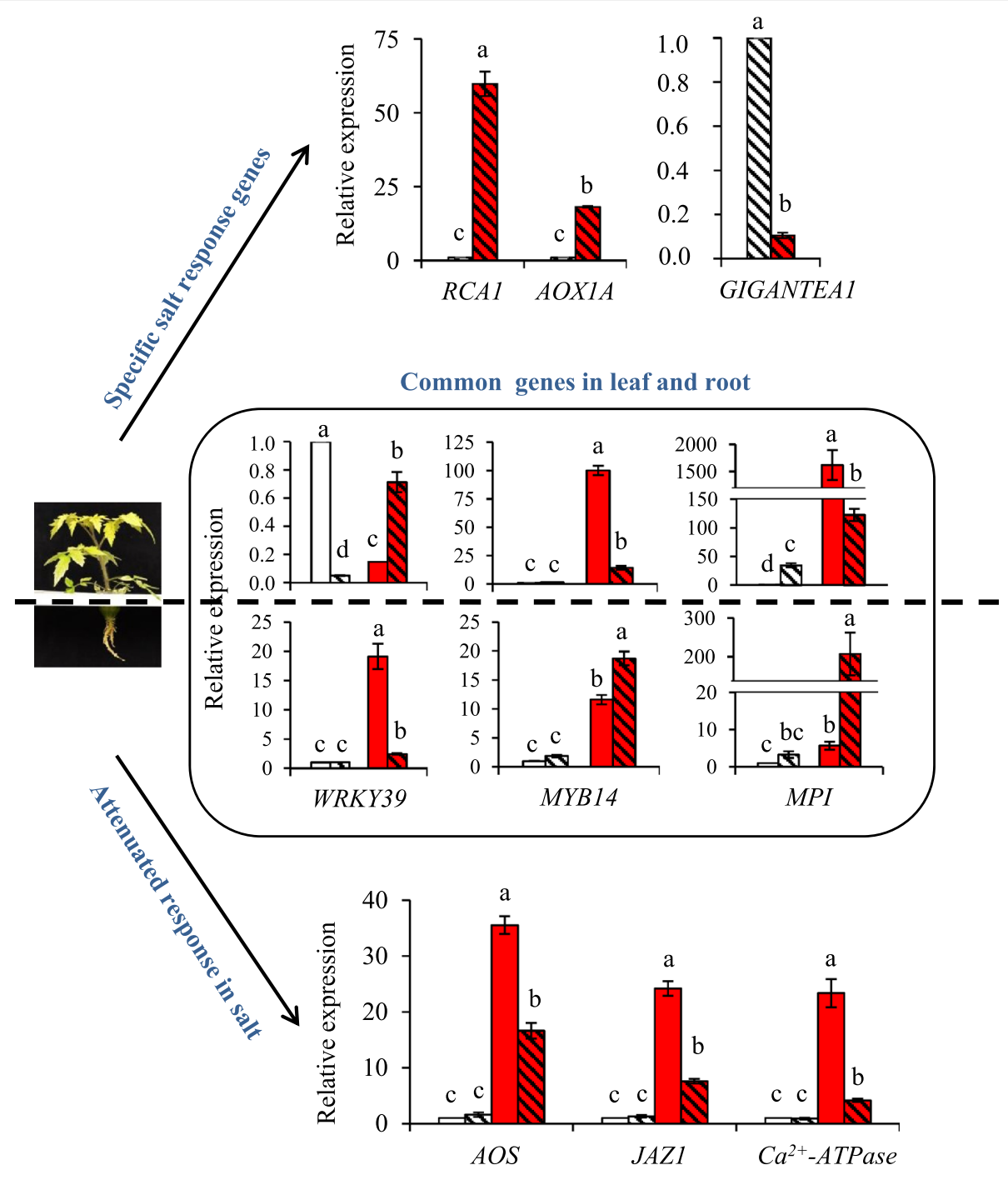

$\square$ WT-Control $\mathbf{\nabla}$ WT-Salt $\square$ res-Control $\mathbf{v}$ res-Salt

Fig. 3 RT-qPCR analysis of relevant DEGs between WT and res in absence of salt stress (Control) and after 5 days at $200 \mathrm{mM} \mathrm{NaCl}$ (Salt). Specific salt response genes were analyzed in leaf (GIGANTEA, RCA1 and AOXIA), common genes in both plant parts (SIWRKY39, SIMYB14 and MPI), and genes of JA and $\mathrm{Ca}^{2+}$ signaling (AOS, JAZ1 and $\mathrm{Ca}^{2+}$-ATPase) in roots. Values are means $\pm \mathrm{SE}$ of three biological replicates. Different letters indicate significant differences between means by LSD test $(P<0.05)$

gene analysed was MPI, and the data corroborated that this PI was highly up-regulated in leaves, especially in control, and also in res roots during salt stress (Fig. 3).

In order to validate the microarray data, additional DEGs were analysed by RT-qPCR in roots and leaves (Additional file 11: Figure S4). Comparison of microarray and RT-qPCR results showed the same trend in relative gene expression, and a Pearson's correlation coefficient of 0.87 was obtained (Additional file 11: Figure S4). In summary, the RT-qPCR data verified the reproducibility and reliability of the microarray analysis.

\section{Discussion}

The phenotype of res mutant is largely associated to the high constitutive expression of genes involved in stress responses and repression of genes related to growth and development in roots

The phenotype of res mutant comprises severe morphological and physiological dysfunctions and a high accumulation of the stress hormone JA in roots in absence of stress, while these alterations are suppressed by salinity [13]. A first question was to elucidate whether the development alterations in the res mutant were due to the high constitutive expression of stress genes. The comparative transcriptomic 
analysis between WT and res strongly supports that constitutive alterations in gene expression in roots account in great part for the phenotypical disorders of res mutant, as in control, the number of DEGs in res vs WT was 3-fold higher in roots than in leaves (3046 and 1019 DEGs, respectively) (Fig. 2a).

The root has a key role in abiotic stress such as salinity, as it is the first organ that enters in contact with salt and, consequently, its efficiency in stress detection and response mechanisms is determinant for stress tolerance $[2,3]$. In this sense, the anticipated stress response of res roots before application of salinity, and the high number of altered genes in salt-stressed vs non-stressed res roots differs from the discrete response observed in WT roots upon salt stress (Additional file 2: Figure S2a). Among these, we hardly found DEGs in WT roots belonging to main functional categories, in contrast to res roots where numerous DEGs were detected (Tables 1-5). Thus, the transcriptomic analysis showed a constitutive enhanced expression of genes involved in JA biosynthesis (AOS, LOX3) and signalling (JAZ) in res roots (Table 1), which agrees with our previous results in JA accumulation [13]. Different studies indicate that JA and ET signalling often operate synergistically to activate mechanisms of abiotic stress tolerance [21], which also seems to occur in res roots, as several genes encoding $E R F S$ were constitutively up-regulated in res roots in control conditions (Table 1). Interestingly, we also observed the up-regulation in res roots of numerous $\mathrm{Ca}^{2+}$ signalling genes (Table 2), which steer a multitude of downstream responses, as recently exemplified by studies on the function of $\mathrm{Ca}^{2+}$-ATPase [22]. The $\mathrm{Ca}^{2+}$ signalling aspects are beginning to be understood but still there is a great lack of information [23].

In agreement with the fact that hormones act as central integrators of stress adaptation signalling cascades, coordinating the transcriptional regulation of TFs and downstream genes [7], we also observed the up-regulation in res roots of TFs such as WRKYs and MYBs (Table 3), and a relatively high abundance of genes encoding stress-related proteins (Table 4), as lipid transfer proteins, which are involved in key physiological processes [24]. It is also interesting to mention that some of the genes encoding stress-related proteins identified are commonly associated with biotic stresses (Table 4), which agrees with our previous suggestions on the tolerance of the res mutant to multiple abiotic and biotic stresses [15].

On the other hand, growth-promoting genes were repressed in res vs WT roots in absence of stress but not under stress condition (Table 6), which agrees with the phenotypic normalisation shown by res mutant under salinity. This response is contrary to the generalized behaviour of plants, and similar to that observed in some wild tomato species and other halophytes, showing high expression levels of stress-relevant genes in absence of stress, which are determinant to their tolerance, but it usually provokes slower plant growth due to the energetic cost $[16,25]$.

\section{The phenotype recovery induced by salt stress in res mutant is mainly related to the attenuated response in root and enhanced in leaves}

We observed that transcriptomic differences between res and WT were very attenuated in roots in salt stress (the number of DEGs was reduced by $90 \%$ compared to control) (Fig. 2a). In addition, we found that expression differences of genes involved in JA and ET metabolism, signalling pathways, TFs and stress-related proteins were significantly reduced or disappeared in salt, which was mainly due to the down-regulation of these genes comparing res mutant in salt vs control (Tables $1-4)$. These results relate the normalisation of res phenotype with an attenuated stress response in roots. The allocation of resources towards higher growth in res roots under salt stress is also supported by the significant up-regulation of genes involved in developmental processes (i.e. extensins, expansins and other cell wall modification genes) in salt-treated res roots compared to control, while the opposite trend was observed in WT plants (Table 6). This might reflect the higher salt-sensitivity of WT compared to res observed in the long-term [13].

On the other hand, the number of DEGs between res and WT was almost five times higher in leaves than in roots under salt stress (1366 vs 295 DEGs) (Fig. 2a), being stress-related proteins one of the functional categories with higher increase of DEGs in salt vs control (Fig. 2c). Taking into account that many stress-responsive genes display circadian expression [26], it is interesting to point out that salt-specific expression differences were observed for a group of circadian clock genes when res leaves were compared to those of WT, which were mainly a consequence of high expression levels in WT in salt vs control (Table 3). In this sense, [27] indicated that slower circadian rhythms allow better adaptation of the cultivated tomato to the long summer days (usually characterised by stressful environmental conditions), and our results suggest that this may be occurring in the response of the res mutant to salinity. Thus, the two principal components of the central oscillator, $C C A 1$ and TOC1, where $C C A 1$ acts as a repressor of TOC1 expression [28], were identified in our study. Moreover, other key clock components, i.e. ELF4, CO, $F K F-1$, the JmJC TF and GIGANTEA (GI) were down-regulated in res leaves vs those of WT in salt (Table 3 ). What is more, it has been reported that gi mutants are markedly salt tolerant, by exhibiting continued growth under salinity [16], as observed in res mutant. This 
observation agrees with the fact that GI is considered a negative regulator of salt tolerance, and precisely GI expression was strongly induced by salinity in WT (Table 3).

Finally, it is convenient to take into account that a significant amount of the genes detected do not have a known function or have not been functionally annotated to a specific process involved in the stress response (Fig. 2c), and thus they may also have a role, yet unknown, in the growth phenotype and salt response of res mutant. While in res roots most genes with unknown function were identified in control, in leaves the number of unknown DEGs was higher in salt than in control (Fig. 2c).

Genes encoding MYB and WRKY transcription factors and protein metabolism may play prominent roles in the phenotype normalisation and salt tolerance shown by res mutant under salt stress

Only 14 genes differentially expressed in roots and leaves independently of the treatment were identified in the microarray analysis, including WRKY39 and MYB14. The importance of $W R K Y$ and $M Y B$ genes in abiotic stress tolerance is well known [29, 30], although their roles in the salt tolerance of tomato are still scarcely known [31,32]. We recently identified the ARS1 gene, the first MYB of type R1 identified in tomato, which is involved in salt tolerance by regulating stomatal closure during stress and avoiding the high transport of $\mathrm{Na}^{+}$up to the leaves [33]. Interestingly, in our transcriptomic study, ARS1 was specifically salt-upregulated in res leaves compared to WT. Also SIMYB48 (Table 3), a tomato homologous of OsMYB48-1 which is known to enhance drought and salinity tolerance in rice [34]. Moreover, the Arabidopsis thaliana AtWRKY40, which is homologous to the SlWRKY39 identified in this work, is known to stimulate JA-signalling by supressing JAZ repressors [35]. Both WRKY39 and MYB14 genes seem to have a role in the phenotype of res and its normalisation under salt stress, according to their expression profiles in roots and leaves of the mutant compared to WT (Fig. 3). Moreover, both genes showed opposite expression trends in res roots and leaves upon salinity, which suggests that they are specifically regulated in each tissue. Finally, it is interesting to point out that MYB14 is one of the few genes increasing its expression in res roots in salt stress compared to control (Fig. 3).

The maintenance of protein homeostasis, i.e. the balance between protein biosynthesis and degradation, is crucial for plant survival [36]. We found remarkable expression differences between WT and res plants, in both tissues and treatments, for genes related to protein metabolism, especially those encoding proteases and PIs (Table 5). PIs have been generally associated to biotic stress responses [37], although they also seem to play important roles in abiotic stress responses, as adaptation to stress requires the active balance between regulated proteolysis and inhibition of uncontrolled proteolysis [38]. The overexpression of a cysteine protease inhibitor from Jatropha curcas in transgenic Nicotiana benthamiana conferred increased salinity tolerance along with lower MDA contents [39]. As PIs were highly up-regulated in res leaves in both conditions (Table 5), this could explain the constitutive lower MDA levels found in res leaves (Fig. 1c). One outstanding gene is MPI (Solyc07g007250.2.1), which showed the highest up-regulation in res leaves compared to WT, especially in control but also in salt stress. Moreover, MPI was highly up-regulated in res roots during salt stress (Fig. 3). Together, these results suggest that MPI, and probably other PIs genes, may have a role in the salt tolerance of res.

\section{The specific salt-upregulation of key genes involved in photosynthesis explain the enhancement of photosynthetic efficiency and phenotype recovery in res mutant}

Under salinity, res plants were able to restore a normal phenotype and cell structure, including that of chloroplasts [13]. This fact explained the remarkable recovery of the greenish colour in leaves under salt stress, which was reflected in the increase in leaf chlorophyll content (Fig. 1c). Furthermore, an important physiological sign of salt tolerance in res mutant was the increase of the photosynthetic efficiency during salinity (Fig. 1c). Interestingly, only in some cases of halophytes, an increase in the photosynthetic activity with salinity may occur [40]. The increased photosynthetic efficiency of res was accompanied by specific salt-upregulation of genes involved in photosynthesis in the mutant compared to WT. Remarkably, the DEG with the highest fold change in salt-treated res leaves respect to WT was RCA1 (Table 7). One important problem for improving plant productivity is optimizing the efficiency of Rubisco, as it is an extremely inefficient enzyme and needs a conformational repair, which is mediated by RCA [41]. In this sense, efforts to increase crop yields by bioengineering Rubisco remain unsuccessful [42]. By RT-qPCR we confirmed that $R C A 1$ was strongly upregulated in res leaves under salt stress compared to WT (Fig. 3). These higher expression levels in res may favour Rubisco reparation and its efficiency under salt stress.

Another gene with high up-regulation in res leaves compared to WT specifically in salt stress was AOX1A (Table 7, Fig. 3). AOX is able to efficiently oxidize the excess of reducing equivalents coming from chloroplast via the malate valve $[43,44]$. In agreement, one of the genes conforming the malate valve, the chloroplast-localized GLYCERALDEHYDE-3-PHOSPHATE DEHYDROGENASE (GAPDH) (Solyc07 g005390.2.1), was also up-regulated in res leaves under salt 
stress. Moreover, different studies revealed the importance of AOX pathway in optimizing photosynthesis under abiotic stress [45-48]. Thus, Arabidopsis plants overexpressing AOX displayed a higher relative growth rate than WT plants under drought stress [49], and in breeding studies, $A O X$ was suggested as a marker to bring about efficient cell reprogramming during growth and development under stressful conditions [50]. Finally, although to lower levels, genes involved in light-reactions of photosynthesis were also specifically overexpressed in res leaves compared to WT under salt stress (Table 7), as FED-A and PGR5 involved in electron flow in PSI, and PspB gene coding for a key protein of the PSII reaction centre.

Remarkably, all the genes related to photosynthetic efficiency were down-regulated in leaves of salt-treated WT plants compared to non-stressed leaves, especially RCA1 and AOX1A (Table 7). The down-regulation of these genes in WT, along with those involved in developmental processes (i.e. expansins, extensins) are indicative of detrimental stress effects in WT plants, although physiological symptoms were not visible yet after 5 days of treatment. However, the increased growth and salt tolerance of the res mutant compared to WT plants may be related with the higher expression in salinity of key genes involved in optimizing photosynthesis, especially $R C A 1$ and $A O X 1 A$.

\section{Conclusions}

The res mutant shows a remarkable growth penalty in absence of stress according to the high basal expression, especially in roots, of numerous genes involved in stress responses, from hormone metabolism, signalling, transcription factors, to other stress-related genes. However, the constitutive up-regulation of stress responses in res mutant confers a benefit upon exposure to salt stress and favour its phenotypic recovery, which is accompanied, on the one hand, by the attenuation of gene expression differences in roots and, on the other hand, by the enhancement of gene expression differences in leaves. In this sense, the down-regulation of GIGANTEA1, which is considered a negative regulator of salt tolerance, and the higher expression of genes involved in photosynthesis optimization, especially $R C A 1$ and $A O X 1 A$, may explain the higher photosynthetic efficiency and phenotypic recovery of res under salt stress. Remarkably, there are few DEGs between res and WT detected simultaneously in roots and leaves independently of the treatment, and these include SIWRKY39, SIMYB14 and MPI, which seem to have a prominent role in the phenotype recovery of the mutant and its salt tolerance. Overall, our results illustrate how genes with different primary functions may work synergistically and coordinately in order to ensure successful plant adaptation to changing environmental conditions. Finally, we hope this work will provide new valuable information in order to enhance future breeding programs for stresstolerant tomato crops.

\section{Methods}

Plant material and salt stress treatment

Plants of the tomato res mutant and Solanum lycopersicum L. cv. Moneymaker (wild-type, WT), were used in this work. Seeds were germinated in darkness, in a 8:3 $(v / \mathrm{v})$ mixture of peat:perlite, at $28{ }^{\circ} \mathrm{C}$ temperature and $90 \%$ of relative humidity $(\mathrm{RH})$. After emergence, plants were grown in a controlled growth chamber with $16 \mathrm{~h}$ light $/ 8 \mathrm{~h}$ darkness photoperiod, with light of a photosynthetic photon flux $(400-700 \mathrm{~nm})$ of $350 \mu \mathrm{mol} \mathrm{m} \mathrm{m}^{-2} \mathrm{~s}^{-1}$ at the plant level, provided by fluorescent tubes (Philips Master TL-D $58 \mathrm{~W} /$ 840 REFLEX, Holland), and $25{ }^{\circ} \mathrm{C}$ and $50-60 \%$ of temperature and $\mathrm{RH}$, respectively. Two-week old plantlets were transferred to hydroponics. The hydroponic system consisted in tanks of $50 \mathrm{~L}$ volume $(219 \times 20 \times 17 \mathrm{~cm})$ filled with half-strength $(1 / 2)$ Hoagland nutritive solution [51], which was continuously aerated by means of a compressor (Puska N-150-150, with a $115 \mathrm{~L} \mathrm{~min}^{-1}$ flow, $10 \mathrm{Kg} \mathrm{cm}^{-2}$ maximum pressure). The nutritive solution was controlled by monitoring $\mathrm{pH}$ and electrical conductivity (EC), renewing it at least once per week.

Salt stress was applied to six-week old WT and res plants, and consisted in $1 / 2$ Hoagland plus $200 \mathrm{mM} \mathrm{NaCl}$ as previously described [13]. Two previous assays were carried out in order to select the time of salt exposure where the phenotype recovery of res mutant began to be visible, and a time period of 5 days of salt stress was selected (Additional file 1: Figure S1). To avoid osmotic shock, $100 \mathrm{mM} \mathrm{NaCl}$ was applied during the first day and then $200 \mathrm{mM} \mathrm{NaCl}$ until the end of the treatment. Physiological measurements and harvesting of leaves (1st fully-expanded) and roots for molecular analyses were carried out in non-treated plants (control) and in plants salt-stressed for 5 days.

\section{Physiological measurements}

All physiological measurements were determined in two independent salt stress assays, including three biological replicates (of three plants each one) per genotype and treatment. Chlorophyll content was analyzed in the 1st fully-developed leaf of WT and res plants by means of a portable device SPAD-502 that measures chlorophyll fluorescence (Minolta, Kyoto, Japan). The Soil Plant Analysis Development (SPAD) units given by the equipment are correlated with the plant chlorophyll content [52]. Three measurements were taken in different areas of the leaf, and the average value was obtained. Chlorophyll fluorescence was also analyzed by means of a portable Chlorophyll Fluorometer (Opti-Sciences, Hudson, NH). This equipment obtains the maximal 
photochemical efficiency of photosystem II estimated as $\mathrm{Fv} / \mathrm{Fm}=\left(\mathrm{Fm}-\mathrm{F}_{0}\right) / \mathrm{Fm}$, where $\mathrm{Fv} / \mathrm{Fm}$ is the ratio between the variable fluorescence and the maximal fluorescence. $\mathrm{Fm}$ is the maximal fluorescence intensity in leaves adapted to darkness during $30 \mathrm{~min}$, induced by a far red light excitation source $\left(3000 \mu \mathrm{mol} \mathrm{m}{ }^{-2} \mathrm{~s}^{-1}\right)$ during $0.8 \mathrm{~s}$. $\mathrm{F}_{0}$ is the minimal fluorescence intensity due to the exposition of leaves to an actinic light source $\left(400 \mu \mathrm{molm}^{-2} \mathrm{~s}^{-1}\right)$ [53].

Malondialdehyde (MDA) was quantified in leaflets from first fully-expanded leaves, as indicative of lipid peroxidation using the thiobarbituric acid reactive substrates (TBARS) assay, using the protocol described in [54] with slight modifications. Briefly, $0.5 \mathrm{~g}$ of leaflet tissue was homogenized in $4 \mathrm{~mL}$ of $0,1 \%$ trichloroacetic acid (TCA) solution using a Polytron (Kinematica AG, Switzerland). The homogenate was centrifuged at $15000 \mathrm{~g}$ for $10 \mathrm{~min}$ and $0.5 \mathrm{~mL}$ of the supernatant obtained was added to $1.5 \mathrm{~mL} 0.5 \%$ thiobarbituric acid (TBA) in $20 \%$ TCA. The mixture was incubated at $90{ }^{\circ} \mathrm{C}$ in a shaking water bath for $30 \mathrm{~min}$, and the reaction was stopped by placing the reaction tubes in an ice-water bath. The samples were then centrifuged at $1000 \mathrm{~g}$ for $5 \mathrm{~min}$, and the absorbance of supernatant was read at $532 \mathrm{~nm}$. The value for non-specific absorption at $600 \mathrm{~nm}$ was subtracted. The amount of MDA-TBA complex (red pigment) was calculated from the extinction coefficient $155 \mathrm{~m} / \mathrm{M} \mathrm{cm}$. Results were expressed as nmol MDA produced per gram of fresh weight per hour (nmol MDA $g^{-1} h^{-1}$ ).

Data were statistically analysed using the SPSS 19.0 software package by two-way ANOVA, with means separated by least significant difference (LSD) $(P<0.05)$. All data are given as mean \pm standard error (SE). Significant differences between means are denoted by different letters.

\section{Microarray analysis and data deposition}

Microarray hybridization was performed in the Molecular Biology Section from Servicio de Apoyo a la Investigación (Universidad de Murcia, Spain). RNA isolated from leaflets (first fully-expanded leaf) and roots coming from three individual pooled plants (biological replicates) was used in hybridization to one chip, resulting in total 24 chips (three biological replicates for each genotype, tissue and treatment). RNA extraction was performed with RNeasy Mini kit (Qiagen, Hilden, Germany) according to manufacturer's instructions, and the amount and quality of the RNA checked by Bioanalyzer and spectrophotometrically by Nanodrop ${ }^{\circ}$ ND-2000 spectrophotometer (ThermoScientific, Waltham, MA, USA). ss-cDNA was synthetized from $100 \mathrm{ng}$ of each sample using the GeneChip WT PLUS Reagent kit (Affymetrix, Santa Clara, CA, USA), according to the protocol supplied by the manufacturer. After quality-checked by Nanodrop and
Bioanalyzer, ss-cDNA targets were cleaned up, fragmented and terminal-labelled. Then, $3.5 \mu \mathrm{g}$ of fragmented and biotinylated ss-cDNA were included in the hybridization mix, using the Hybridization, Wash and Stain kit (Affymetrix) according to manufacturer's recommendations. The resulting preparations were hybridized to the GeneChip ${ }^{\circ}$ Tomato Gene 1.1 ST Array Strip (Affymetrix) offering whole-transcriptome coverage with 26 unique probes for each transcript (a total of 67,795 sequences are interrogated). After scanning, microarrays data were processed using Affymetrix Expression Comand Console (Affymetrix) and all samples (24 samples) overcame the quality criteria for hybridization and labelling tests. Data analysis were then performed with RMA (Robust Multiarray Average) allowing that raw intensity values were background corrected, $\log _{2}$-transformed and then quantile normalized in order to obtain an individual intensity value for each probeset. Non-supervised Principal Components Analysis (PCA) and hierarchical clustering were performed and they showed that samples tend to separate according to genotype and condition. Partek Genomics Suite and Partek Pathways software (Partek Incorporated, St. Louis, USA) were used for obtaining the annotation of probesets and performing the statistical analysis. An ANOVA test was applied with a restrictive threshold at $p$-value $\leq 0.05$, and multiple test corrections was performed using the False Discovery Rate (FDR) [55]. Genes with FDR $<0.05$ and fold change (ratio value) of $\geq 2.0$ when comparing genotypes in the same experimental condition, or comparing different experimental conditions for each genotype, were identified as differentially expressed genes (DEGs). For the functional study of DEGs, Mapman software was used [20]. The Slyc_ITAG2.3 mapping was loaded and used for this functional analysis. The statistical analysis followed was of Wilcoxon Rank Sum test with Benjamini-Hochberg correction.

The microarray data and related analysis information from this work were deposited in NCBI's Gene Expression Omnibus [56] and are accessible through accession number GSE106149 (https://www.ncbi.nlm.nih.gov/geo/ query/acc.cgi?acc=GSE106149).

\section{Quantitative real-time PCR analysis}

The expression levels of 14 selected genes (Additional file 12: Table S1) were analysed by quantitative real-time PCR (RT-qPCR) in order to validate the microarray expression profiles. $5 \mu \mathrm{g}$ of total RNA extracts from roots and leaves of WT and res plants coming from the microarray experiment were used for cDNA synthesis with the First Strand cDNA Synthesis Kit (ThermoScientific, Waltham, MA, USA). $1 \mu \mathrm{g}$ of the cDNA sample was used for gene amplification using the SYBR Green PCR Master Mix (Applied Biosystems, Foster City, CA, USA). Amplification reactions were carried 
out in a CFX Connect $^{\mathrm{TM}}$ Real-Time PCR System (Bio-Rad, Hercules, CA, USA). All primers used for quantitative RT-qPCR are listed in Additional file 12: Table S1. Serial dilutions of cDNA samples were used to make a standard curve in order to calculate the amplification efficiency of primers (Additional file 12: Table S1). The presence of a single peak in the melting temperature curve confirmed the specificity of RT-qPCR amplification. Relative expression data were calculated as described by [57] using the elongation factor 1 (EF1 , Solyc06g005060) as house-keeping gene. The expression level was calculated using $2^{-\Delta \Delta \mathrm{Ct}}$ method [58], considering the expression level from WT as the calibrator sample. Three independent biological replicates were considered, each one consisting in three plants.

\section{Additional files}

Additional file 1: Figure S1. WT and res mutant plants grown in hydroponics. The upper image shows plants grown in absence of stress (control). The lower image shows plants exposed to salt stress (200 mM $\mathrm{NaCl}$ for 5 days), where the reversion of the res phenotype is evident. (PPTX 1579 kb)

Additional file 2: Figure S2. Gene expression differences in WT and res plants comparing salt stress ( $200 \mathrm{mM} \mathrm{NaCl}$ for 5 days) and control conditions. (a) Venn diagrams showing the number of differentially expressed genes (DEGs) in roots (left) and leaves (right) when comparing salt stress vs control in WT and res plants. Numbers in parentheses are the total number of DEGs for each genotype and tissue. DEGs were identified as having FDR $<0.05$ and a minimum fold-change value of 2.0. (b) Ranking of functional categories representing most number of DEGs in each tissue, according to Mapman classification, both in WT and res plants. (PPTX $67 \mathrm{~kb}$ )

Additional file 3: Table S2. Mapman classification of DEGs involved in hormone metabolism in roots (sheet 1) and leaves (sheet 2) of res and WT plants in absence of salt stress (Control) and after 5 days of $200 \mathrm{mM}$ $\mathrm{NaCl}$ (Salt). (XLSX $75 \mathrm{~kb}$ )

Additional file 4: Table S3. Mapman classification of DEGs involved in signalling in roots (sheet 1) and leaves (sheet 2) of res and WT plants in absence of salt stress (Control) and after 5 days of $200 \mathrm{mM} \mathrm{NaCl}$ (Salt). (XLSX $114 \mathrm{~kb})$

Additional file 5: Table S4. Mapman classification of DEGs encoding transcription factors in roots (sheet 1) and leaves (sheet 2) of res and WT plants in absence of salt stress (Control) and after 5 days of $200 \mathrm{mM} \mathrm{NaCl}$ (Salt). (XLSX $115 \mathrm{~kb}$ )

Additional file 6: Table S5. Mapman classification of DEGs encoding stress-related proteins in roots (sheet 1) and leaves (sheet 2) of res and WT plants in absence of salt stress (Control) and after 5 days of $200 \mathrm{mM}$ $\mathrm{NaCl}$ (Salt). (XLSX 69 kb)

Additional file 7: Table S6. Mapman classification of DEGs involved in protein metabolism in roots (sheet 1) and leaves (sheet 2) of res and WT plants in absence of salt stress (Control) and after 5 days of $200 \mathrm{mM} \mathrm{NaCl}$ (Salt). (XLSX 79 kb)

Additional file 8: Table S7. Mapman classification of DEGs involved in developmental processes in roots (sheet 1) and leaves (sheet 2) of res and WT plants in absence of salt stress (Control) and after 5 days of 200 mM NaCl (Salt). (XLSX 120 kb)

Additional file 9: Table S8. Mapman classification of DEGs involved in photosynthesis and related processes in leaves of res and WT plants in absence of salt stress (Control) and after 5 days of $200 \mathrm{mM} \mathrm{NaCl}$ (Salt). (XLSX $33 \mathrm{~kb})$
Additional file 10: Figure S3. Mapman stress diagrams. Differentiallyexpressed genes (DEGs) between res and WT in control and salt-stressed roots and leaves (200 mM NaCl for 5 days) involved in stress responses. Positive fold change values (red) indicate up-regulation (minimum foldchang of 2.0) in res mutant compared to WT in each condition, whereas negative fold change values (blue) indicate down-regulation (minimum fold-change of -2.0 ). Each coloured square represents an individual DEG. (PPTX $1566 \mathrm{~kb}$ )

Additional file 11: Figure S4. (a) Selected genes for completing the validation of the microarray analysis, apart from those shown in Fig. 3, and relative expression values obtained by RT-qPCR using the $\Delta \Delta \mathrm{Ct}$ method, where RNA from either leaflet or root tissue of WT plants grown in control was used as calibrator sample. Values are means \pm SE of three biological replicates. (b) Correlation analysis between microarray ( $x$-axis) and RT-qPCR (y-axis) data. The relative expression values obtained by microarray were compared with those obtained by RT-qPCR, and the Pearson's correlation coefficient (R) was obtained $(R=0.87, n=39)$.

(PPTX $77 \mathrm{~kb}$ )

Additional file 12: Table S1. List of primers used for quantitative realtime RT-PCR. (XLSX $12 \mathrm{~kb}$ )

\section{Abbreviations}

AOX: ALTERNATIVE OXIDASE; cDNA: Complementary deoxyribonucleic acid; DEG: Differentially Expressed Gene; EC: Electrical Conductivity; ERF: ETHYLENE RESPONSE FACTOR; ET: Ethylene; FC: Fold-change; FDR: False Discovery Rate; GI: GIGANTEA; HSP: Heat Shock Protein; JA: Jasmonic Acid/Jasmonate; LSD: Least Significant Difference; LTP: Lipid Transfer Protein; MDA: Malondialdehyde; MPI: METALLOCARBOXYPEPTIDASE INHIBITOR; $\mathrm{NaCl}$ : Sodium chloride; PCA: Principal Component Analysis; PI: Protease Inhibitor; PR: Pathogenesis-related protein; RCA: RUBISCO ACTIVASE; res: Restored cell structure by salinity; RH: Relative Humidity; RMA: Robust Multiarray Average; RNA: Ribonucleic acid; RT-qPCR: Quantitative reverse transcription polymerase chain reaction; SE: Standard Error; SPAD: Soil Plant Analysis Development; ss-cDNA: Single-stranded CDNA; TBA: Thiobarbituric Acid; TBARS: Thiobarbituric Acid Reactive Substrates; TCA: Trichloroacetic Acid; TF: Transcription Factor; WT: Wild-Type

\section{Acknowledgements}

We acknowledge support of the publication fee by the CSIC Open Access Publication Support Initiative through its Unit of Information Resources for Research (URICI). I.A. thanks the Spanish Ministry of Economy and Competitiveness for her FPI research contract (BES-2013-063526).

\section{Funding}

This work was supported by the grants AGL2015-64991-C3-1-2-R from the Spanish Ministry of Economy (MINECO, Spain).

\section{Availability of data and materials}

All the microarray data and analysis information from this work were deposited in NCBI's Gene Expression Omnibus under accession number GSE106149 (https://www.ncbi.nlm.nih.gov/geo/query/ acc.cgi?acc=GSE106149).

\section{Authors' contributions}

$M C B, F B F, R L$ and IE conceived and designed the research. IA, BM and CC performed the laboratory experiments, collection and analysis of data. IA, IE and MCB wrote the manuscript. $R L$ critically revised the manuscript for important intellectual content. MCB, FBF and RL obtained funding. All authors read and approved the final manuscript.

\section{Ethics approval and consent to participate}

Not applicable.

\section{Consent for publication}

Not applicable.

Competing interests

The authors declare that they have no competing interests. 


\section{Publisher's Note}

Springer Nature remains neutral with regard to jurisdictional claims in published maps and institutional affiliations.

\section{Author details \\ 'Departamento de Biología del Estrés y Patología Vegetal, Centro de Edafología y Biología Aplicada del Segura, CSIC, Campus Universitario Espinardo, 30100 Murcia, Spain. ${ }^{2}$ Centro de Investigación en Biotecnología Agroalimentaria (BITAL), Universidad de Almería, 04120 Almería, Spain.}

Received: 15 November 2017 Accepted: 23 September 2018 Published online: 01 October 2018

\section{References}

1. United Nations. 2010-2020: UN decade for deserts and the fight against desertification. http://www.un.org/en/events/desertification_decade/ whynow.shtml (2010). Accessed 20 Aug 2017.

2. Zhu J-K. Abiotic stress signaling and responses in plants. Cell. 2016;167(2): 313-24.

3. Deinlein U, Stephan AB, Horie T, Luo W, Xu G, Schroeder J. Plant salttolerance mechanisms. Trends Plant Sci. 2014;19(6):371-9.

4. Xiong L, Schumaker KS, Zhu J-K. Cell signaling during cold, drought, and salt stress. Plant Cell. 2002;14(Suppl):S165-83.

5. Bergey DR, Kandel R, Tyree BK, Dutt M, Dhekney SA. The role of calmodulin and related proteins in plant cell function: an ever-thickening plot. Springer Science Reviews. 2014;2:145-59.

6. Bari R, Jones JDG. Role of plant hormones in plant defence responses. Plant Mol Biol. 2009;69(4):473-88

7. Xia X-J, Zhou Y-H, Shi K, Zhou J, Foyer CH, Yu J-Q. Interplay between reactive oxygen species and hormones in the control of plant development and stress tolerance. J Exp Bot. 2015:66(10):2839-56.

8. Wasternack C, Hause B. Jasmonates: biosynthesis, perception, signal transduction and action in plant stress response, growth and development. Ann Bot. 2013;111(6):1021-58.

9. Wasternack C. Action of jasmonates in plant stress responses and development — applied aspects. Biotechnol Adv. 2014;32(1):31-9.

10. Ismail A, Seo M, Takebayashi Y, Kamiya Y, Eiche E, Nick P. Salt adaptation requires efficient fine-tuning of jasmonate signalling. Protoplasma. 2014; 251(4):881-98.

11. Golldack D, Li C, Mohan H, Probst N. Tolerance to drought and salt stress in plants: unraveling the signaling networks. Front Plant Sci. 2014:5:151.

12. Yang D-L, Yao J, Mei C-S, Tong X-H, Zeng L-J, Li Q, et al. Plant hormone jasmonate prioritizes defense over growth by interfering with gibberellin signaling cascade. Proc Natl Acad Sci U S A. 2012;109(19):E1192-200.

13. Garcia-Abellan JO, Fernandez-Garcia N, Lopez-Berenguer C, Egea I, Flores FB, Angosto $\mathrm{T}$, et al. The tomato res mutant which accumulates JA in roots in non-stressed conditions restores cell structure alterations under salinity. Physiol Plant. 2015:155(3):296-314.

14. Grebner W, Stingl NE, Oenel A, Mueller MJ, Berger S. Lipoxygenase6dependent oxylipin synthesis in roots is required for abiotic and biotic stress resistance of Arabidopsis. Plant Physiol. 2013;161(4):2159-70

15. Garcia-Abellan JO, Albaladejo I, Egea I, Flores FB, Capel C, Capel J, et al. The phenotype alterations showed by the res tomato mutant disappear when the plants are grown under semi-arid conditions: is the res mutant tolerant to multiple stresses? Plant Signal Behav. 2016. https://doi.org/10.1080/ 15592324.2016.1146847.

16. Park HJ, Kim W-Y, Yun D-J. A new insight of salt stress signaling in plant Mol Cells. 2016;39(6):447-59.

17. Egea I, Albaladejo I, Meco V, Morales B, Sevilla A, Bolarin MC, Flores FB. The drought-tolerant Solanum pennellii regulates leaf water loss and induces genes involved in amino acid and ethylene/jasmonate metabolism under dehydration. Sci Rep. 2018;8:2791.

18. FAOSTAT. FAO statistics. Food and Agriculture Organization of the United Nations. (2014). http://www.fao.org/faostat/en/\#home. Accessed 17 Aug 2017

19. Larrieu A, Vernoux T. Q\&a: how does jasmonate signaling enable plants to adapt and survive? BMC Biol. 2016;14:79.

20. Thimm O, Bläsing $O$, Gibon $Y$, Nagel A, Meyer S, Krüger $P$, et al. Mapman: a user-driven tool to display genomics data sets onto diagrams of metabolic pathways and other biological processes. Plant J. 2004;37(6):914-39.
21. Kazan K. Diverse roles of jasmonates and ethylene in abiotic stress tolerance. Trends Plant Sci. 2015:20(4):219-29.

22. Kudla J, Becker D, Grill E, Hedrich R, Hippler M, Kummer U, Parnisk M, Romeis T, Schumacher K. Advances and current challenges in calcium signalling. New Phytol. 2018. https://doi.org/10.1111/nph.14966.

23. Yang DL, Shi Z, Bao Y, Yan J, Yang Z, Yu H, Li Y, Gou M, Wang S, Zou B et al. 2017. Calcium pumps and interacting BON1 protein modulate calcium signature, stomatal closure, and plant immunity. Plant Physiol. 2017;175:424-437.

24. Liu F, Zhang X, Lu C, Zeng X, Li Y, Fu D, et al. Non-specific lipid transfer proteins in plants: presenting new advances and an integrated functional analysis. J Exp Bot. 2015;66(19):5663-81.

25. Albaladejo I, Meco V, Plasencia F, Flores FB, Bolarin MC, Egea I. Unravelling the strategies used by the wild tomato Solanum pennellii to confront salt stress: from leaf anatomical adaptations to molecular responses. Environ Exp Bot. 2017;135:1-12.

26. Seo PJ, Mas P. STRESSing the role of the plant circadian clock. Trends Plant Sci. 2015;20(4):230-7.

27. Müller NA, Wijnen CL, Srinivasan A, Ryngajllo $\mathrm{M}$, Ofner I, Lin $\mathrm{T}$, et al. Domestication selected for deceleration of the circadian clock in cultivated tomato. Nat Genet. 2016:48:89-93.

28. Gendron JM, Pruneda-Paz JL, Doherty CJ, Gross AM, Kang SE, Kay SA. Arabidopsis circadian clock protein, TOC1, is a DNA-binding transcription factor. Proc Natl Acad Sci U S A. 2012;109(8):3167-72.

29. Li C, Ng CK-Y, Fan LM. MYB transcription factors, active players in abiotic stress signaling. Environ Exp Bot. 2015;114:80-91.

30. Phukan UJ, Jeena GS, Shukla RK. WRKY transcription factors: molecular regulation and stress responses in plants. Front Plant Sci. 2016;7:760.

31. Huang S, Gao Y, Liu J, Peng X, Peng X, Niu X, Fei Z, et al. Genome-wide analysis of WRKY transcription factors in Solanum lycopersicum. Mol Gen Genomics. 2012;287(6):495-513.

32. Li Z, Peng R, Tian Y, Han H, Xu J, Yao Q. Genome-wide identification and analysis of the MYB transcription factor superfamily in Solanum lycopersicum Plant Cell Physiol. 2016:57(8):1657-77.

33. Campos JF, Cara B, Perez-Martin F, Pineda B, Egea I, Flores FB, et al. The tomato mutant ars 1 (altered response to salt stress 1) identifies an R1-type MYB transcription factor involved in stomatal closure under salt acclimation. Plant Biotechnol J. 2016:14(6):1345-56.

34. Xiong H, Li J, Liu P, Duan J, Zhao Y, Guo X, et al. Overexpression of OSMYB48-1, a novel MYB-related transcription factor, enhances drought and salinity tolerance in rice. PLoS One. 2014;9(3):e92913.

35. Brotman Y, Landau U, Cuadros-Inostroza Á, Tohge T, Fernie AR, Chet I, et al, Trichoderma-plant root colonization: escaping early plant defense responses, and activation of the antioxidant machinery for saline stress tolerance. PLoS Pathog. 2013;9(3):e1003221.

36. Kidric M, Kos J, Sabotic J. Proteases and their endogenous inhibitors in the plant response to abiotic stress. Botanica Servica. 2014;38(1):139-58.

37. Martel C, Zhurov V, Navarro M, Martinez M, Cazaux M, Auger P, et al. Tomato whole genome transcriptional response to Tetranychus urticae identifies divergence of spider mite-induced responses between tomato and Arabidopsis. Mol Plant-Microbe Interact. 2015:28(3):343-61.

38. Sun X, Wang F, Cai H, Zhao CH, Ji W, Zhu Y. Functional characterization of an Arabidopsis prolyl aminopeptidase AtPAP1 in response to salt and drought stresses. Plant Cell Tissue Organ Culture. 2013;114(3):325-38.

39. Li R, Wang W, Wang W, Li F, Wang $Q$, Xu Y, et al. Overexpression of a cysteine proteinase inhibitor gene from Jatropha curcas confers enhanced tolerance to salinity stress. Electron J Biotechnol. 2015;18(5):368-75.

40. Redondo-Gomez S, Mateos-Naranjo E, Figueroa ME, Davy AJ. Salt stimulation of growth and photosynthesis in an extreme halophyte, Arthrocnemum macrostachyum. Plant Biol. 2010;12(1):79-87.

41. Bracher A, Whitney SM, Hartl FU, Hayer-Hartl M. Biogenesis and metabolic maintenance of Rubisco. Annu Rev Plant Biol. 2017:68:29-60.

42. Bhat JY, Thieulin-Pardo G, Hartl FU, Hayer-Hartl M. Rubisco activases: AAA+ chaperones adapted to enzyme repair. Front Mol Biosci. 2017:4:20.

43. Taniguchi M, Miyake H. Redox-shuttling between chloroplast and cytosol: integration of intra-chloroplast and extra-chloroplast metabolism. Curr Opin Plant Biol. 2012;15(3):252-60

44. Zhang L-T, Zhang Z-S, Gao H-Y, Meng XL, Yang C, Liu JG, et al. The mitochondrial alternative oxidase pathway protects the photosynthetic apparatus against photodamage in Rumex K-1 leaves. BMC Plant Biol. 2012;12:40. 
45. Vanlerberghe GC. Alternative oxidase: a mitochondrial respiratory pathway to maintain metabolic and signaling homeostasis during abiotic and biotic stress in plants. Int J Mol Sci. 2013;14(4):6805-47.

46. Vishwakarma A, Tetali SD, Selinski J, Scheibe R, Padmasree K. Importance of the alternative oxidase (AOX) pathway in regulating cellular redox and ROS homeostasis to optimize photosynthesis during restriction of the cytochrome oxidase pathway in Arabidopsis thaliana. Ann Bot. 2015;116(4):555-69.

47. Dinakar C, Vishwakarma A, Raghavendra AS, Padmasree K. Alternative oxidase pathway optimizes photosynthesis during osmotic and temperature stress by regulating cellular ROS, malate valve and antioxidative systems. Front Plant Sci. 2016;7:68

48. Vanlerberghe GC, Martyn GD, Dahal K. Alternative oxidase: a respiratory electron transport chain pathway essential for maintaining photosynthetic performance during drought stress. Physiol Plant. 2016;157(3):322-37.

49. Skirycz A, De Bodt S, Obata T, De Clerca I, Claeys H, De Rycke R, et al. Developmental stage specificity and the role of mitochondrial metabolism in the response of Arabidopsis leaves to prolonged mild osmotic stress. Plant Physiol. 2010;152(1):226-44

50. Arnholdt-Schmitt B, Costa JH, de Melo DF. AOX - a functional marker for efficient cell reprogramming under stress? Trends Plant Sci 2006; 11(6):281-287.

51. Hoagland DR, Arnon DI. The water-culture method for growing plants without soil. Calif Agricultural Experiment Stn Circular. 1950;347:1-32.

52. Hoel BO, Solhaug KA. Effect of irradiance on chlorophyll estimation with the Minolta SPAD-502 leaf chlorophyll meter. Ann Bot. 1998;82(3):389-92.

53. Maxwell K, Johnson GN. Chlorophyll fluorescence-a practical guide. J Exp Bot. 2000;51(345):659-68.

54. Sanchez-Bel P, Egea I, Sanchez-Ballesta MT, Martinez-Madrid C, FernandezGarcia N, Romojaro F, et al. Understanding the mechanisms of chilling injury in bell pepper fruits using the proteomic approach. J Proteome. 2012; 75(17):5463-78.

55. Benjamini $Y$, Hochberg $Y$. Controlling the false discovery rate - a practical and powerful approach to multiple testing. J R Statist Soc B. 1995;57(1):289-300.

56. Edgar R, Domrachev M, Lash AE. Gene expression omnibus: NCBI gene expression and hybridization array data repository. Nucleic Acids Res. 2002; 30(1):207-10.

57. Asins MJ, Villalta I, Aly MM, Olías R, Alvarez de Morales P, Huertas R, et al. Two closely linked tomato HKT coding genes are positional candidates for the major tomato QTL involved in $\mathrm{Na}^{+} / \mathrm{K}^{+}$homeostasis. Plant Cell Environ. 2013;36(6):1171-91.

58. Livak KJ, Schmittgen TD. Analysis of relative gene expression data using real-time quantitative PCR and the 2(-Delta Delta $C(T))$ method. Methods. 2001;25(4):402-8.

Ready to submit your research? Choose BMC and benefit from:

- fast, convenient online submission

- thorough peer review by experienced researchers in your field

- rapid publication on acceptance

- support for research data, including large and complex data types

- gold Open Access which fosters wider collaboration and increased citations

- maximum visibility for your research: over $100 \mathrm{M}$ website views per year

At $\mathrm{BMC}$, research is always in progress.

Learn more biomedcentral.com/submissions 